\title{
Virtual reality experiences promote autobiographical retrieval mechanisms: Electrophysiological correlates of laboratory and virtual experiences
}

\author{
Joanna Kisker ${ }^{1} \cdot$ Thomas Gruber $^{1} \cdot$ Benjamin Schöne ${ }^{1}$
}

Received: 22 April 2020 / Accepted: 1 September 2020 / Published online: 15 September 2020

(c) The Author(s) 2020

\begin{abstract}
Recent advancements in memory research indicate that virtual reality (VR) experiences are more vividly memorized as compared to conventional laboratory events. In contrast to the latter, VR experiences are highly immersive, simulating the multimodality, vividness and inclusiveness of real-life experiences. Therefore, VR might enable researchers to identify memory processes underlying events which participants have actually experienced, in contrast to conventional on-screen experiences. To differentiate the electrophysiological correlates of memory processes underlying VR experiences as compared to conventional laboratory experiences, participants watched videos either in a PC condition or in a VR condition, followed by an unannounced recognition memory test. As hypothesized, we replicated the well-established theta old/new effect for the PC condition, but remarkably, this effect was absent in the VR condition. Additionally, the latter was accompanied by significantly lower alpha activity as compared to the PC condition. As increases in theta-band responses are related to topdown control on, and memory load during retrieval, the observed theta responses might rather relate to retrieval effort than to retrieval success per se. Congruently, higher alpha activity measured over occipital sensor areas in the PC condition reflect visually guided search processes within episodic memory. The VR condition comes in with lower alpha activity, reflecting immediate and effortless memory access. Hence, our findings indicate that the retrieval of VR experiences promotes autobiographical retrieval mechanisms, whereas recalling conventional laboratory events comes in with higher effort, which might not reflect the mechanisms of everyday memory.
\end{abstract}

\section{Introduction}

How people behave in everyday life strongly depends on previous experiences either with a particular situation or personal general knowledge, e.g. concerning the realization of own goals, acting effectively and relating to other peoples (see Conway, 2005). This kind of information is predominantly encoded in and retrieved from autobiographical memory (AM). Similar to episodic memory (EM), autobiographical engrams encode personally experienced events

Electronic supplementary material The online version of this article (https://doi.org/10.1007/s00426-020-01417-x) contains supplementary material, which is available to authorized users.

Joanna Kisker

joanna.kisker@uni-osnabrueck.de

1 Experimental Psychology I, Institute of Psychology, Osnabrück University, Seminarstraße 20, 49074 Osnabrück, Germany in their respective spatial and temporal context (Tulving, 1983). Extending well beyond EM, AM encompasses highly self-relevant information, especially beliefs and knowledge about the self, experienced events and their relevance (see e.g. Conway, 2005; Greenberg \& Rubin, 2003). Hence, AM comprises episodic engrams, extending it by self-referential and emotional processes. The retrieval of autobiographical memories is therefore not limited to temporal, spatial or contextual information, but bears great personal significance (Svoboda, McKinnon, \& Levine, 2006). The retrieval of such everyday memories promotes the re-experience of the associated emotions (Svoboda et al., 2006), coming in with vivid and conscious reliving, and foremost the belief that they have actually occurred (Rubin, Schrauf \& Greenberg 2003; Greenberg \& Rubin, 2003).

While it is common practice to investigate everyday memory in the laboratory using paradigms that induce micro-events prior to recognition memory tests (see Cabeza et al., 2004), these settings are often criticized for lacking the complexity and variety of stimuli and response options 
characteristic to real-life experiences (Pan \& Hamilton, 2018; Kvavilashvili \& Ellis, 2004). Specifically, self-relevance and self-involvement are rarely realized in laboratory settings (see e.g. McDermott, Szpunar, \& Christ, 2009). Obviously, such traditional approaches face a trade-off between high experimental control and ecological validity, i.e. the validity of the results obtained in the laboratory and generalized to everyday life (see Parsons, 2015).

Potentially overcoming this gap between experimental control and ecological validity, virtual reality (VR) has gained interest as a methodical tool in psychological research (see e.g. Parsons, 2015; Pan \& Hamilton, 2018; Schöne et al., 2017, Kisker, Gruber, \& Schöne 2019a, b). For memory research, VR experiences might provide a closer approximation to real-life experiences as compared to conventional laboratory settings. The former is characterized by a high level of sensory cues and thus, by high fidelity of the represented environment (Dan \& Reiner, 2017). Accordingly, VR environments are more pronounced regarding vividness as compared to classical setups (Slater \& Wilbur, 1997), which is also characteristic for AM (Greenberg \& Rubin, 2003). In particular, everyday experiences arise from the complex, multisensory 3D-environment of the real world, while laboratory memories are generated by highly controlled events rather poor in sensory information (Cabeza $\&$ St Jaques, 2007). Moreover, the formation of such memories is accompanied by intuitive and quick monitoring and closely linked to self-referential processing (Moscovitch \& Winocur, 2002; Cabeza \& St Jaques, 2007). Importantly, the latter is as well increased under VR conditions due to its immersive character: VR facilitates an increased sense of presence, i.e. the subjective feeling of being within a virtual environment (VE; e.g. Slater \& Wilbur, 1997; Schubert et al., 2001; Nilsson, Nordahl, \& Serafin, 2016). Whereas immersion predominantly determines the degree to which the user is isolated from his physical surroundings by technical factors, like $3 \mathrm{D}-360^{\circ}$ view and proprioceptive matching, presence promotes the subjective feeling of actually being in and acting within the VE (Slater \& Wilbur, 1997; Nilsson, et al., 2016). Consequently, the sensation of acting within the VE comes in with the impression of being subject to the consequences of these actions and events in the VE (Slater \& Wilbur, 1997; Nilsson, et al., 2016). For example, participant behave as if being in real danger when exposed to dangerous situations in an immersive VE, even though their surroundings could not physically harm them (e.g. Kisker et al., 2019a; Krijn et al., 2004; Gromer et al., 2019). In line, VR setups have been found to elicit the same emotional and physical reactions as compared to their real-life equivalents (Gorini et al., 2010; Higuera-Trujillo et al., 2017). Given this impression of mutual interaction with the virtual surroundings, VR experiences are more personally and emotionally relevant than mere on-screen experiences (see Kisker et al., 2019a; Schöne et al., 2016, Schöne et al. 2019). Hence, VR might improve the possibilities to investigate the mechanisms underlying real-life memory (see Parsons, 2015; Serino \& Repetto, 2018; Schöne et al., 2016, Schöne et al. 2019; Kisker et al., 2019b; Burgess et al., 2001).

Initial studies of memory processes under immersive VR conditions found that retrieval of VR experiences is not only enhanced compared to the retrieval of conventional laboratory micro-events (see e.g. Serino \& Repetto, 2018; Smith, 2019; Schöne et al., 2016, Schöne et al. 2019; Krokos, Plaisant, \& Varshney, 2019; Ernstsen, Mallam \& Nazir, 2019; Harman, Joel, Brown, Ross \& Johnson, 2017), but also provides a closer approximation to real-life memory processes (Schöne et al., 2016; Schöne et al. 2019; Kisker et al., 2019b). In particular, a previous study found evidence that immersive VR experiences become part of an extensive autobiographical associative network, whereas conventional video experiences remain an isolated episodic event (Schöne et al., 2019). Going one step further, the retrieval of VR experiences is proposed to mainly rely on recollection, i.e. vivid and accurate remembering of events (e.g. Atkinson \& Juola, 1973; Jacoby \& Dallas, 1981) which is associated with AM (Roediger \& Marsh, 2003; Conway, 2005). In contrast, retrieval of memories induced by conventional laboratory settings predominantly fall back on familiarity-based mnemonic processes (Kisker et al., 2019b), characterized as a subjective, vague feeling to remember a previous experience (e.g. Curran \& Hancock, 2007; Rugg \& Curran, 2007). Although both groups principally employed both, familiarity and recollection as non-exclusive retrieval mechanisms (see Jones and Jacoby, 2001), one mechanism predominated over the other as a function of the encoding context. Accordingly, encoding in VR resulted in a more precise and vivid retrieval than encoding the same scenario in a PC setup (Kisker et al., 2019b).

Overall, these studies suggest that VR experiences are not just observed, i.e. passively watching stimuli presented on a screen, but experienced in a self-relevant manner. Even interactive PC setups designed as immersive as possible by means of active exploration of a desktop-based environment, generate overall rather superficial engrams compared to exactly the same VE explored as a VR experience (Kisker et al., 2019b). Unlike conventional laboratory experiences, the latter become part of a personal experience like real-life experiences would (Schöne et al., 2016, 2019).

However, while the electrophysiological correlates of, for example, the sense of presence (e.g. Bouchard et al., 2009) and spatial memory (e.g. Rauchs et al., 2008) are recently more widely investigated, findings regarding the electrophysiological correlates of retrieval of episodic and autobiographical engrams encoded within VR are still rare (cf. e.g. Smith, 2019; Serino \& Repetto, 2018; Plancher \& Polino, 2017; Bohil et al., 2011). Accordingly, it is the aim 
of our study to differentiate the electrophysiological correlates of the retrieval of VR experiences as opposed to conventional laboratory experiences. Specifically, we examined a well-established electrophysiological marker of recognition memory tasks by means of the theta old/new effect obtained from laboratory settings (for review see Nyhus \& Curran 2010; Guderian \& Düzel, 2005; Hsieh \& Ranganath, 2014; see also Gruber, Tsivilis, Giabbiconi \& Müller, 2008; Klimesch et al., 1997a, 2001a). Therefore, we examined theta-oscillations ( 4-8 Hz; e.g. Nyhus \& Curran, 2010), which are most prominent at sensors over frontal-midline regions (e.g. Hsieh \& Raganath, 2014). There is broad and stable consensus, that a characteristic theta-band synchronization can be observed in these regions in response to the retrieval of old stimuli, which are correctly remembered, i.e. in response to retrieval success. In contrast, new stimuli are associated with theta-band desynchronization (e.g. Nyhus $\&$ Curran, 2010). This effect was observed both subsequent to the stimulus presentation (e.g. Klimesch et al., 1997b; Klimesch et al., 2001a) and after a physical response of participants, e.g. key pressure (Gruber, Tsivilis, Giabbiconi, \& Müller, Gruber et al., 2008). Moreover, theta-oscillations are associated with recollection of personal events (Guderian \& Düzel, 2005) and hippocampal projections to neocortical frontal regions are regarded as possible generators of these oscillations during memory tasks (e.g. Hsieh \& Ranganath, 2014). In conjunction with the characteristic frontal-midline theta-band synchronization, a decrease of the alpha-band response ( 8-13 Hz, e.g. Berger, 1929) can regularly be observed during memory recall (e.g. Klimesch, et al., 1997b; Sauseng et al., 2009; Jacobs, Hwang, Curran $\&$ Kahana, 2006). This decrease of alpha-band response is regarded a reflection of visual processing (Clayton, Yeung \& Cohen Kadosh, 2018), attentional processes (Klimesch et al., 1997a) and memory load (Sauseng et al., 2009; Jacobs et al., 2006; Jensen \& Tesche, 2002; Dan \& Reiner, 2017). In short, the theta-band synchronizes in response to mental activity, whilst the alpha-band desynchronizes (Berger, 1929 as cited in Klimesch et al., Klimesch, Doppelmayr, Schimke, et al. 1997b).

To examine whether this well-established and robust effect occurs under VR conditions as well, we set up an experiment in which participants incidentally encoded either immersive $3 \mathrm{D}-360^{\circ}$ videos or conventional $2 \mathrm{D}$ videos followed by an unannounced recognition memory test. We assume that the VR condition will result in a higher sense of presence, better memory performance and higher accuracy of memory judgements as compared to the conventional PC condition. Moreover, we hypothesize to replicate the theta old/new effect for the conventional PC condition, manifested significant difference between theta-band responses to old and new stimuli, including a synchronization for old, and a desynchronization for new stimuli (see e.g. Gruber et al.,
2008; Klimesch et al., 1997a, 2001a, b). In line, the alphaband response should significantly decrease for new pictures as compared to old pictures. Concerning the VR condition, different outcomes might be possible: Under the premise that the theta old/new effect is exclusively linked to successful memory retrieval, theta-band synchronization for old stimuli should be higher for the VR condition as compared to the PC condition, as most studies indicate that VR setups enhance memory performance (e.g. Schöne et al. 2016, 2019; Smith, 2019) and activate recollection-based engrams (Kisker et al., 2019b). For the alpha-band, a similar pattern of results might be expected. However, as theta-band oscillations are related to further memory-related processes, e.g. memory load (Nyhus \& Curran, 2010; Jensen \& Tesche, 2002), decision making (Nyhus \& Curran, 2010) and working memory (Hsieh \& Ranganath, 2014), another outcome than the classical effect might be equally likely in the VR condition.

\section{Methods}

\section{Participants}

45 participants were recruited from Osnabrück University. The sample size was determined on the basis of previous studies with a similar study design (cf. Schöne et al., 2019; Kisker et al., 2019a). All participants were screened for psychological and neurological disorders and had normal or corrected-to-normal sight. Three participants were excluded during the anamnesis. When vision correction was necessary, only those participants who had contact lenses could participate, not those who wore glasses. It was ensured that the participants saw sharply on the screen as well as on the head-mounted display. Previous experience with VR environments was documented. All participants gave informed consent and were blind to the research question. The participants received either partial course credits or $15 €$ for participation.

The participants were randomly assigned to both conditions (VR vs. PC). Three participants were excluded from analysis due to insufficient data quality $(n=2)$ and prior knowledge of the stimulus material used for the unannounced recognition memory test $(n=1)$. After exclusion, we obtained 39 complete datasets for analysis (VR group: $n_{\mathrm{VR}}=20, M_{\mathrm{age}}=21.95, \mathrm{SD}_{\mathrm{age}}=3.19,15$ female, 19 righthanded; PC group: $n_{\mathrm{PC}}=19, M_{\mathrm{age}}=22.16, \mathrm{SD}_{\mathrm{age}}=2.32,13$ female, 18 right-handed). 


\section{Encoding}

\section{Stimulus material}

One hundred $3 \mathrm{D}-360^{\circ}$ videos from the Library for Universal Virtual Reality Experiments (luVRe, Schöne, Kisker, Sylvester, Radtke \& Gruber, 2020; https://www.psycho.uniosnabrueck.de/fachgebiete/allgemeine_psychologie_i/ luvre.html) were used as stimulus material. All videos were recorded with the Insta360Pro VR-camera with a frame rate of $60 \mathrm{fps}$ and $4 \mathrm{k}$ resolution. Each video was $10 \mathrm{~s}$ long. The videos were randomly subdivided into targets and distractors for the unannounced recognition memory test in a 50:50 ratio. The themes of the videos were balanced between target and distractor videos (e.g. nature footage, interiors, medical facilities, sport events, social events; see supplementary material for a detailed description of the video content). Only the target videos were presented during incidental learning. Distractor videos were unknown to the participants and only used for the unannounced recognition memory test.

\section{Procedure}

Participants were randomly assigned to the VR- or the PCcondition. For the VR-condition, participants were equipped with a wireless version of the HTC Vive Pro head-mounted display. Video footage and sound were presented in $3 \mathrm{D}-360^{\circ}$, with a resolution of $1080 \times 1200$ pixels per display. Participants were allowed to look around, but not to turn $180^{\circ}$ or walk around.

For the PC-condition, participants were seated in front of a curved monitor (35", $90 \mathrm{~cm}$ screen diagonal, $37 \mathrm{~cm}$ height). The participant's distance to the screen was kept constant at $80 \mathrm{~cm}$. The videos were presented in $2 \mathrm{D}$ videos in full-screen resolution. Sound was presented over standard speakers placed on both sides of the monitor.

For both conditions, the videos were presented in randomized sequences with the GoPro VR Player, providing the same video resolution for both conditions (cf. stimuli). Each randomized sequence was presented to one participant per condition. Each video was preceded by one-second fixation on a fixation cross. To facilitate incidental encoding, the presentation of each video clip was followed by a rating (10 s) as a distraction task (cf. Fig. 1). Participants were instructed to separately rate the experienced valence, arousal and motivation, i.e. their desire to stay in or leave the presented scene for each video separately on a scale from one (bad/not at all) to six (good/very much; cf. Kuhr et al., 2015). The ratings were consecutively presented on the (virtual) screen for $3.33 \mathrm{~s}$ each. The participants were familiarized with the rating before the video presentation. To guarantee for similar visual experience during the rating and maintain immersion, the rating took place in an exact virtual simulation of the laboratory in which the study actually took place, implemented as a $3 \mathrm{D}-360^{\circ}$ video recording of the laboratory. In addition, the rating scales were displayed on the (virtual) monitor during rating phase. For the $\mathrm{PC}$ group, the simulation of the laboratory was displayed as a 2D video as well. The participant's answers were recorded with a dictation device. The ratings regarding valence, arousal and motivation of the videos were collected for the validation of a database and will not be further analyzed in this study. The presentation of the videos took a total of $19 \mathrm{~min}$. To enhance immersion, all test leaders left the lab until the end of the video presentation. The participant was given a bell to
Fig. 1 Procedure of incidental encoding. Each of the 50 target videos was preceded by a fixation on a virtual screen and followed by the rating of valence, arousal and motivation. Each scale was faded in on the virtual screen separately for $3.33 \mathrm{~s}$. During fixation and rating, a $3 \mathrm{D}-360^{\circ}$ image of the laboratory in which the participants were actually located was presented

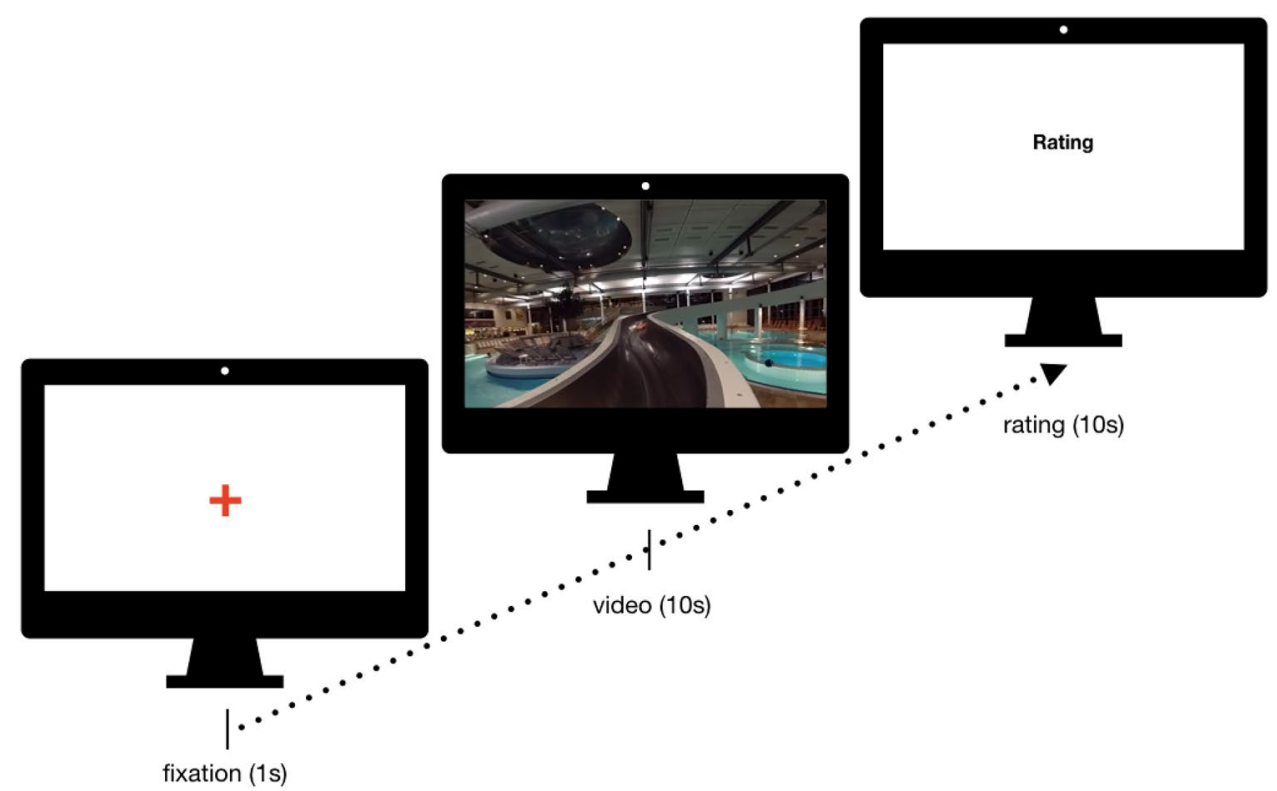


alert the test leaders if they wanted to quit the experiment early or felt uncomfortable.

To determine the sense of presence, participants were asked to fill in the German version of the Igroup Presence Questionnaire (IPQ; Schubert, Friedmann \& Regenbrecht, 2001) and were asked for their experience of physical symptoms (vertigo, nausea). In addition, the participants were instructed not to discuss the videos with the test leaders until the end of the experiment.

\section{Unannounced recognition memory test}

\section{Stimulus material}

Monoscopic screenshots from both, distractors (referred to as new pictures) and targets (referred to as old pictures), were used as stimulus material for the unannounced recognition memory test. Per video, one representative screenshot was utilized as stimulus, resulting in 100 trials. The stimuli were presented on a conventional 24 " monitor with a parafoveal visual angle of $2 \times 5^{\circ}$.

\section{Procedure}

The retention interval was set to $1 \mathrm{~h}$ during which the EEG was applied. If the participants mentioned the videos they had seen during encoding, they were kindly interrupted and asked not to discuss the videos until the end of the experiment. Participants were instructed about their task immediately before the unannounced recognition memory test.

The unannounced recognition test comprised of 100 trials. Per trial, participants had to indicate as fast as possible whether they recognized the presented stimulus as (1) definitely unknown, (2) rather unknown, (3) familiar or (4) vividly remembered (cf. Kisker et al., 2019b). Each trial started with randomly $0.5-0.8 \mathrm{~s}$ fixation, followed by $1.5 \mathrm{~s}$ presentation of the stimulus. The rating scale was then displayed until the participants responded via key pressure. The interstimulus interval lasted randomly between $1.0 \mathrm{~s}$ and $1.5 \mathrm{~s}$ (see Fig. 2). The response options were defined during instruction as follows (translated from German):

(1) Definitely unknown: I'm sure I've not seen this place

(2) Rather unknown: I guess I haven't seen this place

(3) Familiar: This place looks familiar to me

(4) Vividly remembered: I remember this place precisely and vividly.

\section{Electrophysiological recordings and preprocessing}

An electroencephalogram (EEG) with 128 electrodes, attached in accordance with the international 10-20-system was recorded for the duration of the unannounced recognition memory test. The Active-Two amplifier system from BioSemi (Amsterdam, Netherlands) was used. The sampling rate was $1024 \mathrm{~Hz}$, the bandwidth $(3 \mathrm{~dB}) 104 \mathrm{~Hz}$. Additionally, horizontal electrooculogram (hEOG) and vertical electrooculogram (vEOG) were recorded and a common mode sense (CMS) and a driven right leg (DRL) electrode were applied. The EEG was recorded on the investigators' computer using ActiView702 Lores.

EEG data were analyzed using MATLAB. For further off-line analysis, the average reference was used. The EEG was segmented to obtain epochs starting $500 \mathrm{~ms}$ prior and $1500 \mathrm{~ms}$ following stimulus onset (baseline -300 to $-100 \mathrm{~ms}$ ). Artifact correction was performed by means of "statistical correction of artifacts in dense array studies" (SCADS; Junghöfer, Elbert, Tucker, \& Rockstroh, 2000). In brief, this procedure uses a combination of trial rejection and channel approximation based
Fig. 2 Setup of the memory test trials: $0.5-0.8 \mathrm{~s}$ fixation, $1.5 \mathrm{~s}$ stimulus presentation, presentation of the scale until the participant's response, 1.0-1.5 s inter stimulus interval (ISI). Participants were asked not to blink from fixation until the response scale appeared

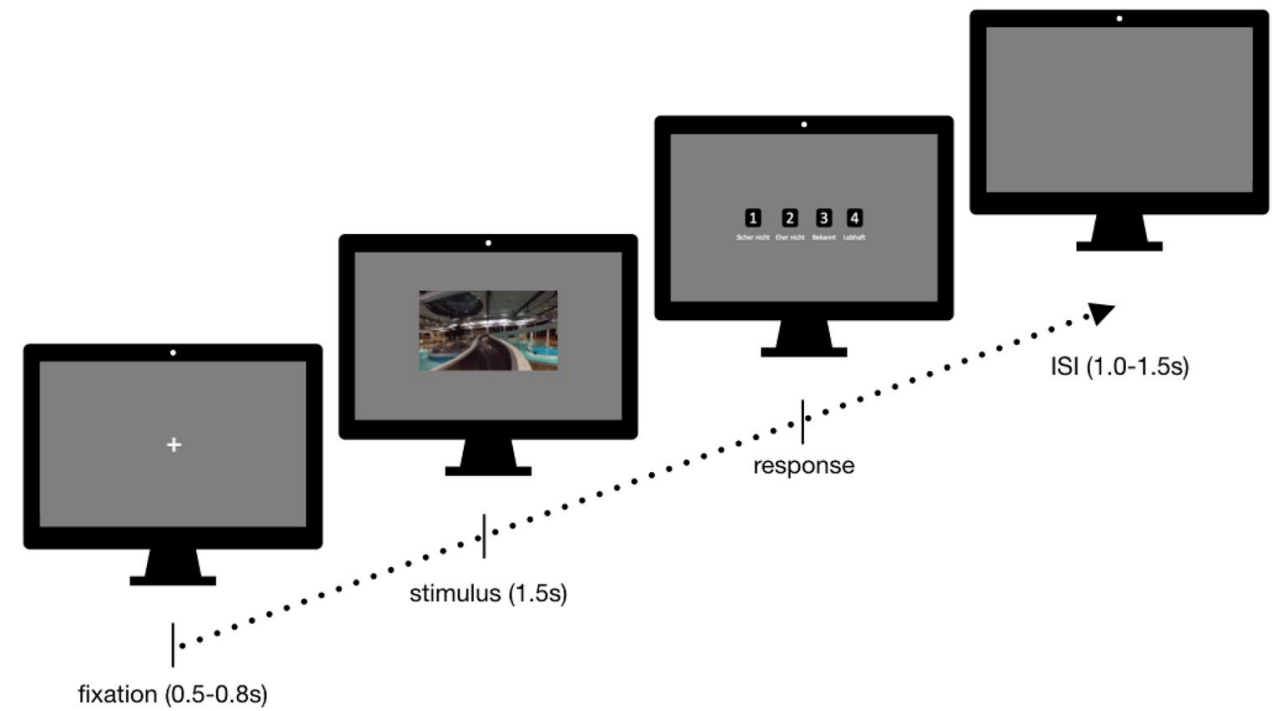


on statistical parameters of the data. For each trial, contaminated electrodes are detected based on a threshold criterion derived from the distribution of the amplitude, standard deviation, and gradient of the sensor across all trials. The information of these electrodes is replaced with a spherical interpolation from the full channel set. The limit for the number of approximated channels was set to 20. Epochs containing more than 20 channels with artifacts were rejected.

For demonstrating a robust signal at the frequency bands of interest, we first calculated a conventional fast Fourier transform (FFT, see Fig. 5) per trial and averaged across all electrodes, conditions and participants.

For further analyses and a comparison between experimental conditions, we considered it advantageous to take the signal's temporal evolution into account. Thus, for the subsequent examinations, spectral changes in oscillatory activity were analysed by means of Morlet wavelets with a width of 12 cycles per wavelet which is described in detail elsewhere (e.g., Tallon-Baudry \& Bertrand, 1999; Bertrand \& Pantev, 1994). In brief, the method provides a time-varying magnitude of the signal in each frequency band, leading to a time-by-frequency (TF) representation of the data. Due to the fact that induced oscillatory activity occurs with a jitter in latency from one trial to another (Eckhorn et al., 1990), they tend to cancel out in the averaged evoked potential. Thus, TF amplitude is averaged across single-trial frequency transformations, allowing one to analyze non-phase-locked components. Furthermore, because we focused on the non-phase-locked components of the signal, the evoked response (i.e., the ERP) was subtracted from each trial before frequency decomposition (for details, see Busch, Herrmann, Müller, Lenz, \& Gruber, 2006). Given our interest in the lower-frequency range, we used wavelets from $0.25 \mathrm{~Hz}$ to $30 \mathrm{~Hz}$.

Based upon prior literature (e.g. Nyhus \& Curran, 2010) and our hypothesis, the frequency range from 4-7 Hz was included in the analyses and checked against visual inspection of the FFT (see Fig. 5). However, visual inspection of the FFT revealed high power for $2-4 \mathrm{~Hz}$ as well. This frequency range is commonly denoted as the delta-band, but was also identified as lower theta-band in some studies, indicating that the old-new effect might be reflected in the 2-4 Hz frequency range as well (cf. Burgess \& Gruzelier, 1997; Klimesch, Schimke \& Schwaiger, 1994; Klimesch et al., 2000). Hence, the $2-4 \mathrm{~Hz}$ response was included in the analyses as well. Electrodes around $\mathrm{Fz}$ covering for the frontal midline region were chosen. Based upon prior literature, an early latency range from 250 to $650 \mathrm{~ms}$ for the $2-4 \mathrm{~Hz}$ response (see Burgess \& Gruzelier, 1997) and 200-600 ms for the 4-7 Hz band response were used for analyses (e.g. Guderian \& Düzel, 2005; Klimesch et al., 1997b; Klimesch, Doppelmayr,
Schwaiger, Winkler \& Gruber, 2000; Klimesch al., 2001b; Jacobs et al., 2006). The alpha frequency band $(8-13 \mathrm{~Hz}$, see e.g. Berger, 1929) was analyzed at electrodes surrounding $\mathrm{Oz}, \mathrm{O} 1$ and $\mathrm{O} 2$ in the time window from 0 to $500 \mathrm{~ms}$.

\section{Statistical analysis}

\section{Presence}

The IPQ scales were determined as sum values of the respective items (in total: 14 items; general presence: one item, spatial presence: five items, involvement: four items, realness: four items). Each item could reach values from -3 and +3 on a 7 -step likert-scale, resulting in the following minimum and maximum sumscores per scale: General Presence $(-3 ; 3)$, Spatial Presence $(-15 ; 15)$, Involvement $(-12$; $12)$, Realness $(-12 ; 12)$.

Shapiro-Wilk-test rejected normal distribution for one of the IPQ scales (General Presence, $p<0.05$ ). Therefore, the more robust Mann-Whitney $U$ test as non-parametric equivalent of the unpaired $t$ test was used for analysis. Cronbach's $\alpha$ was calculated for each scale, with the exception of the one-item-scale General Presence.

\section{Memory performance}

$D^{\prime}$-prime $\left(d^{\prime}\right)$ was calculated separately for both groups as an operationalization of memory performance. $D$ ' relates the hits, i.e. correct positive judgments, to the false-positive judgments ( $d^{\prime}=z$ (hit) $--z$ (false positive); Haatveit et al. 2010; Swets et al., 1961; as cited in Kisker et al., 2019b) and indicates how well participants are able to distinguish between targets and distractors. $D$ '-prime was calculated per group to assess the overall retrieval success (general $d^{\prime}=z$ (all hits $)-z($ all false positives $)$.

Additionally, $d$ ' was separately calculated for familiarity and recollection for each group, taking only the respective hits and false positives into account (cf. Kisker et al., 2019a: $d$ '-familiarity score $=z$ (familiarity hits) $-z$ (familiarity false positives); $d$ '-recollection score $=z$ (recollection hits) $-z$ (recollection false positives). Shapiro-Wilk-test rejected normal distribution for all $d$ ' scores (all $p<0.05$ ). Hence, Mann-Whitney $U$ Test was used for analysis.

Accuracy [(hits + correct rejection)/total number of trials] and error rate [(misses + false positives)/total number of trials] of recognition judgements were calculated per group. Both were analyzed using the unpaired $t$ test. 


\section{Prior VR experience and cybersickness}

Prior experience with VR and cybersickness were assessed as nominal variables (prior experience: "Have you already had any experience with virtual reality, e.g. studies, games or videos?", [yes/no]; cybersickness: "Did you experience physical symptoms such as nausea or dizziness during the experiment?", [yes/no]; if yes: "How strongly did you feel nauseous/dizzy?" [1-10]; cf. Kisker et al., 2019a). Contingency tables and Pearson's Chi square $\left(X^{2}\right)$ test were used for statistical analysis.

\section{Ratings of the videos}

The ratings regarding valence, arousal and motivation of the videos were collected for the validation of a database and will not be further analyzed in this study. To check that the target videos were perceived comparably emotive in both groups, arousal and valence averaged over all 50 target videos were compared between the groups using unpaired $t$ test.

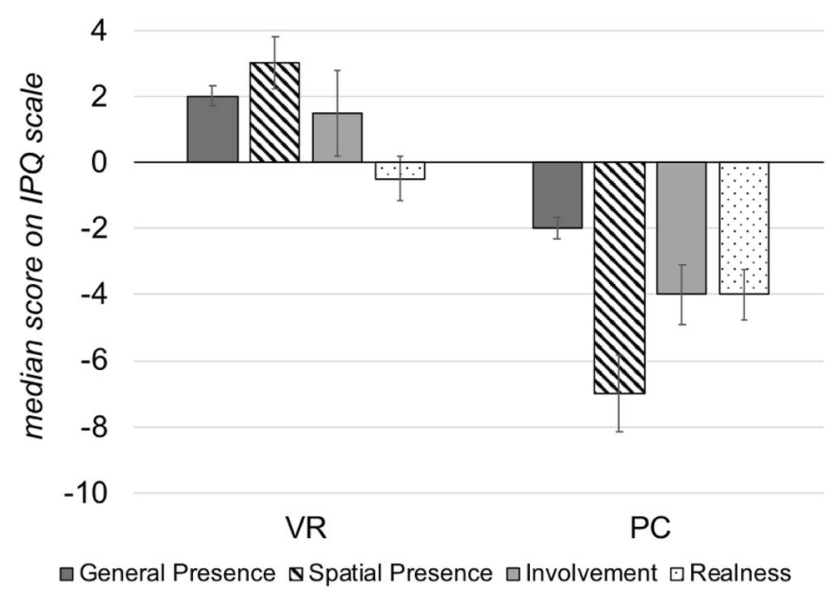

Fig. 3 Median scores of the IPQ scales General Presence, Spatial Presence, Involvement and Realness as evaluated by both groups. The error bars depict the standard error per scale. Minimum and maximum sumscores per scale: General Presence $(-3 ; 3)$, Spatial Presence $(-15 ; 15)$, Involvement $(-12 ; 12)$, Realness $(-12 ; 12)$

\section{Dependent measures}

EEG data were analyzed using a $2 \times 2$ repeated-measurements ANOVA (rmANOVA) with the between-factor "group" (VR vs. PC) and the within-factor "condition" (new pictures vs. old pictures). Significant effects of rmANOVA were complemented by post hoc $t$ tests.

\section{Results}

\section{Subjective measures}

\section{Presence}

As hypothesized, the VR-group reported a higher feeling of presence during video presentation (see Fig. 3). This is valid for all $I P Q$ subscales (all $p \leq 0.005$; see Table 1). Cronbach's $\alpha$ indicates acceptable reliability for all scales (all $\alpha \geq 0.64$ ).

\section{Prior VR experience and cybersickness}

In both groups, about $70 \%$ of the participants had already gained experience with VR prior to the study, e.g. by participating in other studies, watching VR videos or playing VRgames $\left(X^{2}(1)=0.011, p=0.915\right)$. In total, nine subjects $\left(n_{\mathrm{VR}}\right.$ : six, $n_{\mathrm{PC}}$ : three) reported experiencing physical symptoms like nausea and dizziness, but on a very mild level (nausea, in total: $M=2.55, \mathrm{SD}=2.13$; VR: $M_{\mathrm{VR}}=3.33, \mathrm{SD}_{\mathrm{VR}}=2.25$; PC: $M_{\mathrm{PC}}=1.0, \mathrm{SD}_{\mathrm{PC}}=0.0$; dizziness, in total: $M=1.67$, $\mathrm{SD}=1.12 ; \mathrm{VR}: M_{\mathrm{VR}}=2.00, \mathrm{SD}_{\mathrm{VR}}=1.27 ; \mathrm{PC}: M_{\mathrm{PC}}=1.0$, $\mathrm{SD}_{\mathrm{PC}}=0.0$ ), resulting in significantly stronger experiences of physical symptoms in the VR condition $\left(X^{2}(1)=4.91\right.$, $p=0.027$ ).

\section{Ratings of the videos}

Participants of both groups reported equal levels of valence and arousal averaged across all target videos (valence: $M_{\mathrm{VR}}=3.89, \mathrm{SD}_{\mathrm{VR}}=0.52, M_{\mathrm{PC}}=3.61, \mathrm{SD}_{\mathrm{PC}}=0.47$,

and Cronbach's $\alpha$ per scale. Cronbach's $\alpha$ could not be calculated for the one-item-scale General Presence
Table 1 Differences between VR- and PC-group regarding the sensation of presence, assessed via the IPQ (Schubert et al., 2001): Test statistics of the one-tailed Mann-Whitney $U$ test, descriptive values

\begin{tabular}{llllrrr}
\hline IPQ scale & $U$ & $z$ & $p$ & $M d_{\mathrm{VR}}$ & $M d_{\mathrm{PC}}$ & Cronbach's $\alpha$ \\
\hline General presence & 41.00 & -4.29 & $<.001$ & 2.00 & -2.00 & -7.00 \\
Spatial PRESENCE & 19.00 & -4.72 & $<.001$ & 3.00 & -4.00 & 0.68 \\
Involvement & 98.00 & -2.59 & 0.005 & 1.50 & -4.00 & 0.64 \\
Realness & 64.50 & -3.55 & $<.001$ & -0.50 & & 0.70 \\
\hline
\end{tabular}


$t(34)=1.67, p=0.103$; arousal: $M_{\mathrm{VR}}=2.64, \mathrm{SD}_{\mathrm{VR}}=0.55$, $\left.M_{\mathrm{PC}}=2.65, \mathrm{SD}_{\mathrm{PC}}=0.47, t(34)=-0.28, p=0.978\right)$.

\section{Memory performance}

Participants of both groups performed equally well on the unannounced recognition memory test, as none of the calculated $d^{\prime}$ scores revealed significant differences ( $d$ '-general: $U=186.00, z=-0.11, p=0.462 ; d^{\prime}$-familiarity: $U=150.50$, $z=-1.11, p=0.14$; $d^{\prime}$-recollection: $U=162.50, z=-0.77$, $p=0.22$; see Fig. 4).

Moreover, both groups achieved surprisingly high levels of accuracy around $90 \%(t(37)=-0.505, p=0.308$, $\left.M_{\mathrm{VR}}=0.91, M_{\mathrm{PC}}=0.92\right)$ and correspondingly low error rates $\left(t(37)=-0.505, p=0.31, M_{\mathrm{VR}}=0.09, M_{\mathrm{PC}}=0.08\right.$; see Fig. 4), indicating a ceiling effect.

\section{Dependent measures}

Since the behavioral data indicate no difference in memory performance between both groups, and since the high accuracy indicates a ceiling effect, the latency range following stimulus onset was analyzed instead of the latency range following the participants' response (key pressure) to the stimulus (cf. results, memory performance).

The visual inspection of the FFT validated the hypothesis-driven selection of the 4-7 Hz and 8-13 Hz frequency ranges. In addition, the visual inspection also revealed a noticeable power of the $2-4 \mathrm{~Hz}$ frequency range, which is

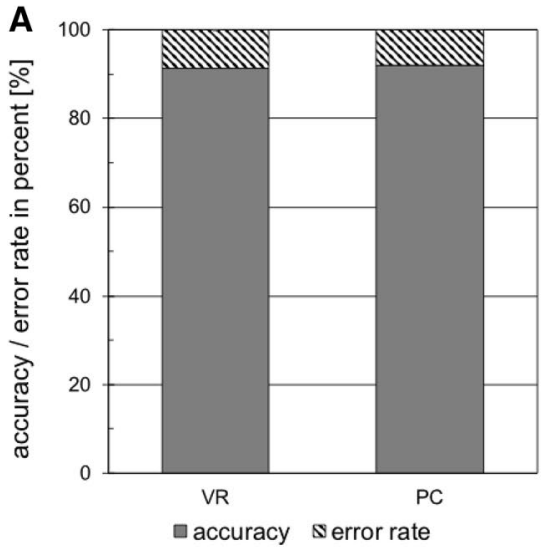

Fig. 4 Panel A depicts the accuracy as well as the respective error rate of the judgement on the recognition or unknown character of the memory task trials in percent for both groups. The error bars depict the standard errors. For accuracy and error rate, the standard error is

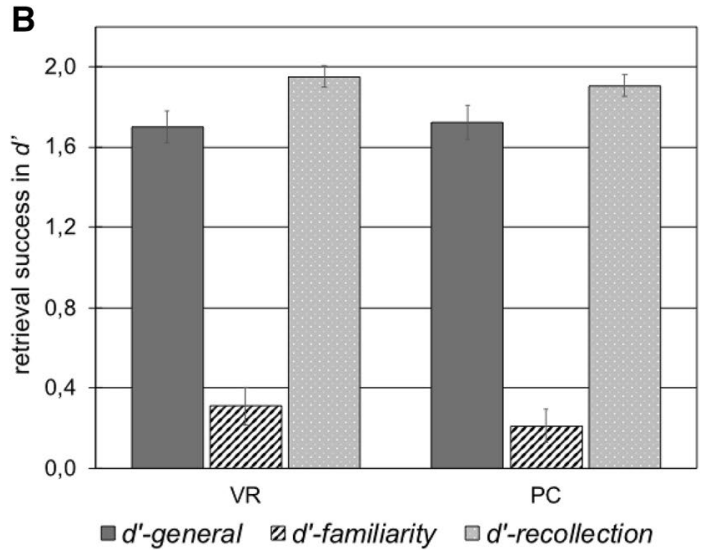

approximately 0.01 and therefore hardly visible in the figure. Panel $\mathrm{B}$ depicts the retrieval success per group operationalized by general d' prime, as well as the d'-familiarity and d'-recollection scores. No significant differences were found between both groups
Fig. 5 Power spectra from fast Fourier transform (FFT) per group and condition. Visual inspection revealed a strong frequency peak from 2 to $4 \mathrm{~Hz}$, which was hence included in the analyses

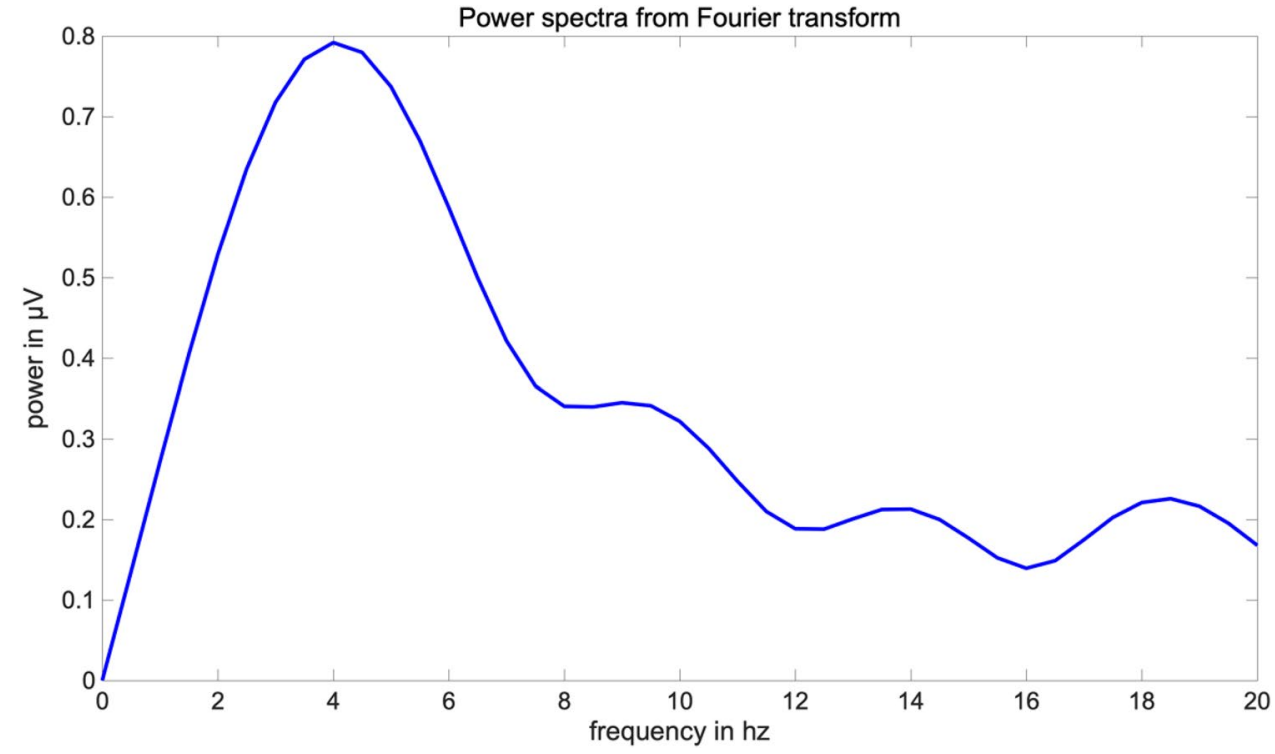


why it was also included in the analyses (see Fig. 5, see methods).

\section{4-7 $\mathrm{Hz}$ responses}

Regarding frontal-midline theta-band responses, no significant main effects could be found $\left(F_{\text {condition }}(1,37)=2.84\right.$, $\left.p=0.10 ; F_{\text {group }}(1,37)=0.38, p=0.543\right)$, but a significant interaction of the factors "group" and "condition" $\left(F_{\text {interaction }}(1,37)=5.03, p=0.046\right)$.

Post-hoc $t$ tests revealed a classical old/new effect in the PC condition with a higher amplitude for old pictures than for new ones $(t(18)=-2.86, p=0.010)$. However, this difference effect was absent within the VR condition $(t(19)=0.25, p=0.805)$. Furthermore, the observed difference effect was comparably larger in the PC-group

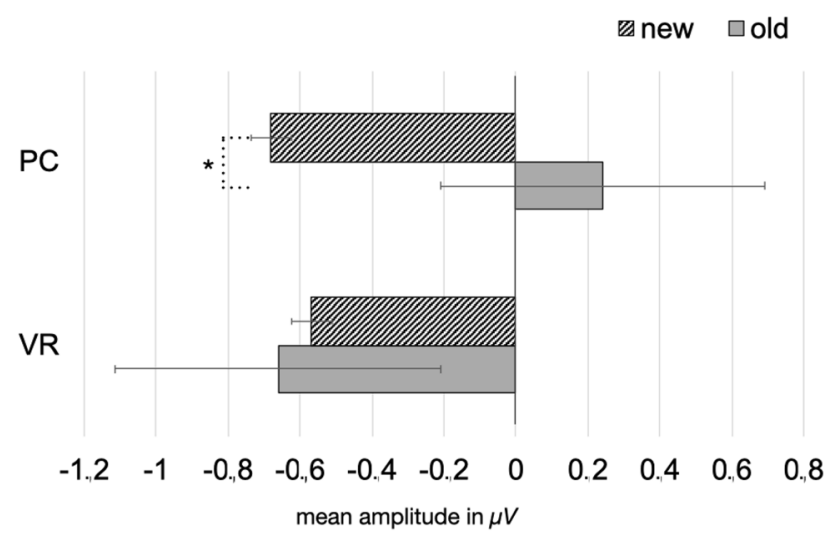

Fig. 6 Mean amplitude in $\mu \mathrm{V}$ regarding the 4-7 $\mathrm{Hz}$ response in the latency range from 200 to $600 \mathrm{~ms}$ after stimulus onset. The error bars depict the standard error of the mean amplitude. Significant differences are marked $(* p<0.05)$ $(t(37)=2.06, p=0.046$; see Figs. 6 and 7). The theta-band response to new pictures $(t(37)=-0.14, p=0.889)$ and to old pictures $(t(37)=1.65, p=0.107)$ did not differ between both groups (see Figs. 6, 7 and 8).

\section{2-4 Hz responses}

For the $2-4 \mathrm{~Hz}$ response, a significant main effect for the factor "condition" $\left(F_{\text {condition }}(1,37)=11.61, p=0.002\right)$, but not for the factor "group" $\left(F_{\text {group }}(1,37)=1.44, p=0.239\right)$ could be found. The main effect of "condition" was further characterized by a significant interaction of both factors $\left(F_{\text {interaction }}(1,37)=4.11, p=0.049\right)$. Following the same trend as the $4-7 \mathrm{~Hz}$ responses, post hoc $t$ tests revealed a classical old/new effect across conditions $(t(38)=3.23$, $p=0.003)$, as well as in the PC condition $(t(18)=-4.74$, $p<0.001)$, but not in the VR condition $(t(19)=-0.85$ $p=0.404)$. Again, the observed difference effect was comparably larger in the PC-group $(t(37)=2.03, p=0.049)$. But most importantly, old pictures elicited greater responses in the PC group compared to the VR-group $(t(37)=2.07, p=0.046)$, whereas responses to new pictures did not differ between both groups $(t(37)=-0.05$, $p=0.96$; see Figs. 9, 10 and 11).

\section{Alpha-band responses}

Regarding the alpha-band responses $(8-13 \mathrm{~Hz})$ at occipital electrodes, a main effect of the factors group $\left(F_{\text {group }}(1,37)=4.26, p=0.046\right)$ and condition $\left(F_{\text {condition }}(1,37)=13.80, p<0.001\right)$, but no significant interaction of both factors was found $\left(F_{\text {interaction }}(1,37)=1.21\right.$, $p=0.278$ ).
Fig. 7 Time-by-amplitude plot of the 4-7 $\mathrm{Hz}$ response from $200 \mathrm{~ms}$ before stimulus onset to $1200 \mathrm{~ms}$ after stimulus onset. While the classical old/ new-effect is also descriptively shown in the PC condition, there are no significant differences between old and new pictures regarding the VRgroup. The gray highlighted section marks the latency range of significant interaction. The amplitude was averaged across the electrodes around $\mathrm{Fz}$, covering for the frontal midline region

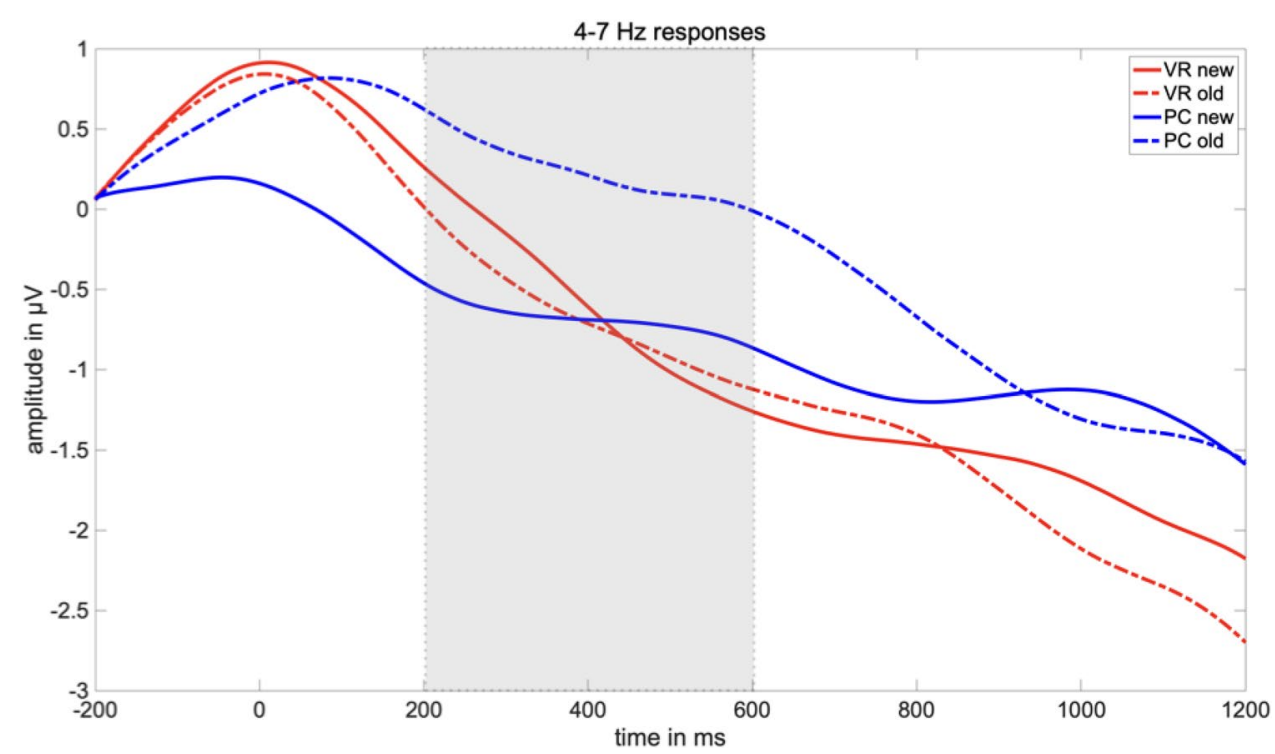


Fig. 8 Topography of the amplitude regarding the $4-7 \mathrm{~Hz}$ response separately for all combinations of the factors group (VR vs. PC) and conditions (old vs. new) in the latency range from 200 to $600 \mathrm{~ms}$ after stimulus onset. Additionally, a difference plot of the old/neweffect is depicted. Black dots mark the electrodes which were included in the analyses
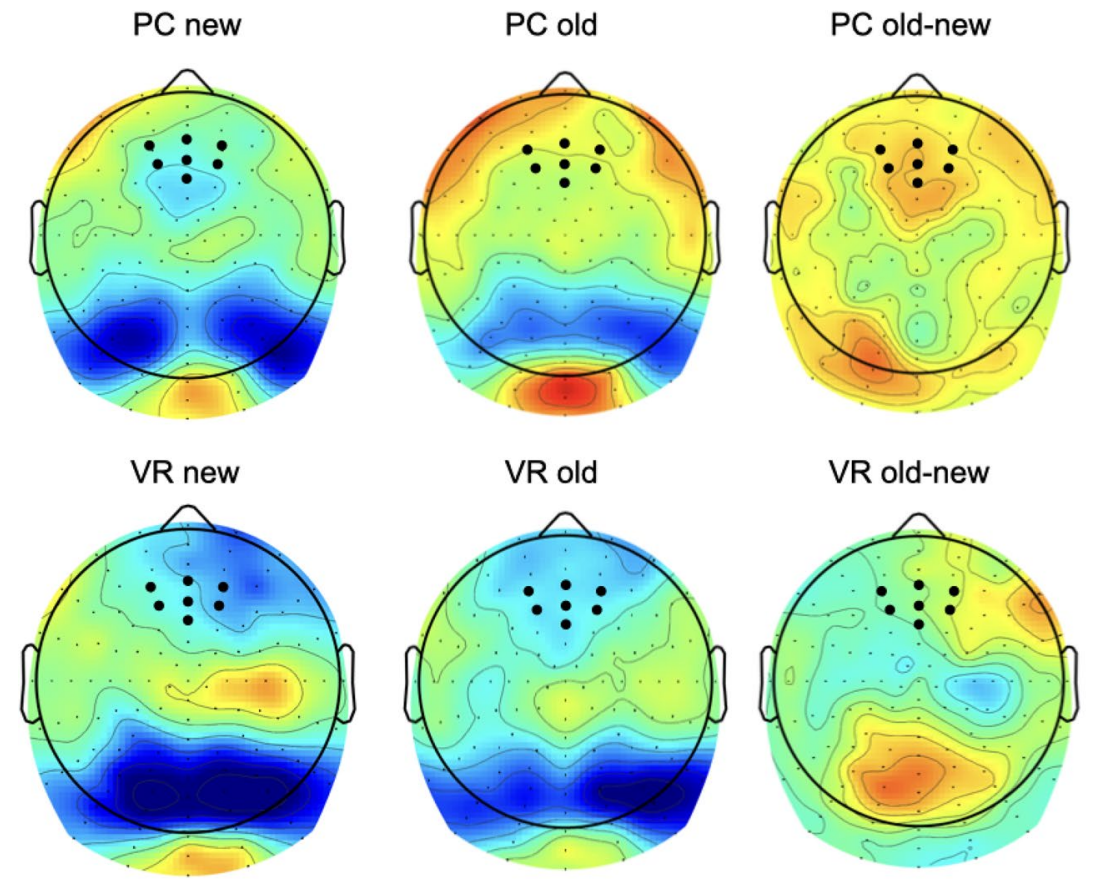

2

$1 \geq$

0

$-1$ -1 을 $-2$
More specifically, new pictures elicited lower alpha amplitudes as compared to old pictures $(t(38)=3.68$, $p<0.001)$. In line, alpha amplitudes were significantly lower for the PC group as compared to the VR group $(t(76)=2.75, p=0.008$; see Figs. 12, 13 and 14).

\section{Discussion}

The aim of the study was to investigate the electrophysiological correlates of the retrieval of VR experiences as opposed to conventional laboratory experiences. To this end, participants watched either $3 \mathrm{D}-360^{\circ} \mathrm{VR}$ videos (VR condition)

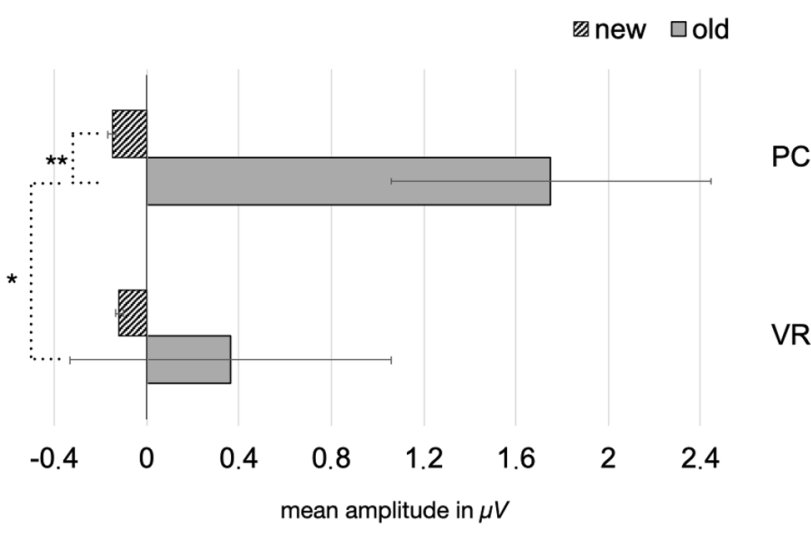

Fig. 9 Mean amplitude in $\mu \mathrm{V}$ regarding the $2-4 \mathrm{~Hz}$ response in the latency range from 250 to $650 \mathrm{~ms}$ after stimulus onset. The error bars depict the standard error of the mean amplitude. Significant differences are marked $(* p<0.05 ; * * p<0.01)$ from the luVRe database (see methods), or watched the exact same stimulus material on a conventional 2D monitor (PC condition). In an unannounced recognition test, we compared their memory performance, the mid-frontal theta old/ new effect indexing mnemonic processing, as well as posterior alpha as a marker for visual processing load. As a result, both groups performed equally well in the recognition test, although the theta old/new effect could only be replicated for the PC condition and was absent in the VR condition. Additionally, the theta effect was accompanied by a profound reduction of posterior alpha in the PC condition, indicating a visually guided, effortful retrieval process.

Meeting our expectations, participants of the VR condition felt more present during video presentation as compared to the PC condition, confirming that our video approach led to immersive VR experiences. Presence, as the most prominent feature of VR experiences (e.g. Schubert et al., 2001, Pan \& Hamilton, 2018; Diemer et al., 2015; Alshaer, Regenbrecht, \& O'Hare, 2017; Riva et al., 2007; Kisker et al., 2019a), is associated with increased emotional involvement (e.g. Gorini et al., 2010; Felnhofer et al., 2015), and stronger and more realistic behavioral responses as compared to conventional laboratory settings (Slobounov et al., 2015; Kisker et al., 2019a). Importantly, previous studies found that a high degree of presence aids memory recall: For example, both intentional encoding, as well as incidental encoding in a VE resulted in a more accurate memory recall as compared to conventional desktop conditions (e.g. Krokos, Plaisant \& Varshney, 2019; Ernstsen, Mallam \& Nazir, 2019). Hence, presence might facilitate encoding processes constituting the VR memory superiority effect (Makowski, Sperduti, 
Fig. 10 Time-by-amplitude plot of the $2-4 \mathrm{~Hz}$ response from $200 \mathrm{~ms}$ before stimulus onset to $1200 \mathrm{~ms}$ after stimulus onset. The gray highlighted section marks the latency range of significant interaction. The amplitude was averaged across the electrodes around $\mathrm{Fz}$, covering for the frontal midline region
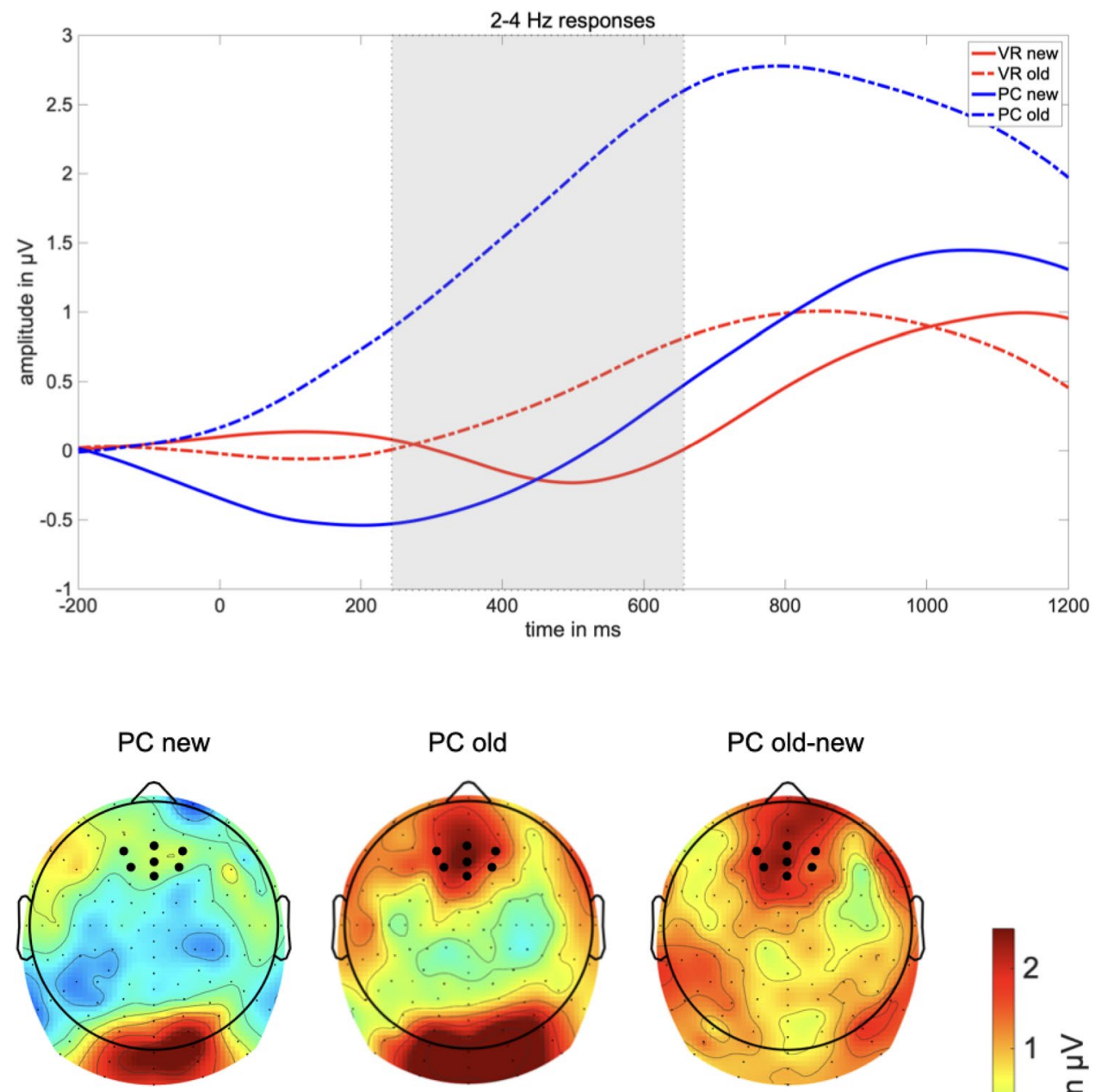

2
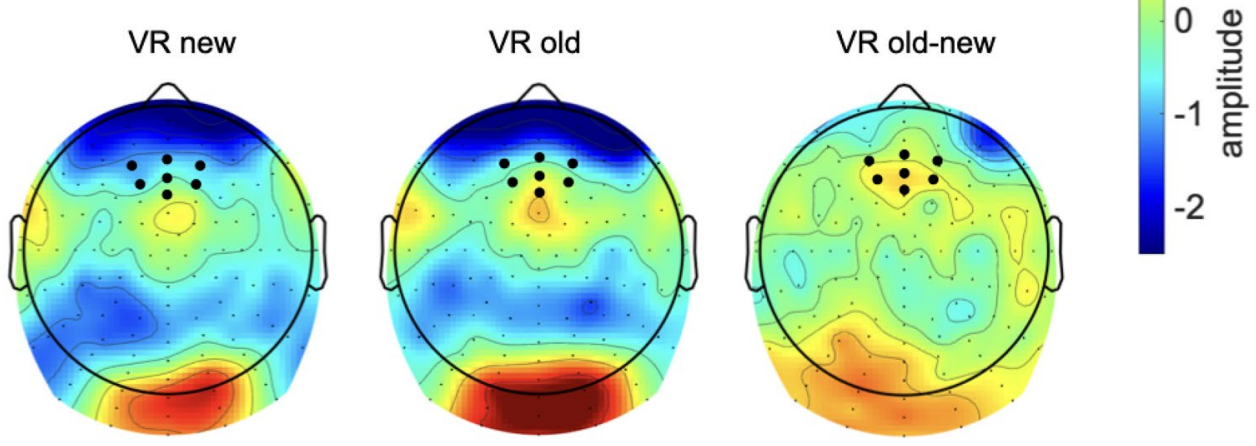

$1 \gtreqless$ .

0

1 हूํำ $-2$

Nicolas \& Piolino, 2017; Serino \& Repetto, 2018; Smith, 2019). In particular, visually detailed environments that provide high realism and resemblance to the real world, such as 3D-360 videos (Pan \& Hamilton, 2018; Lovett et al., 2015), facilitate more accurate judgments in old/new tasks (Smith, 2019). The resulting coherent egocentric perspective facilitates recollection and reliving of such content (see Rubin \& Umanath, 2015), which is crucial to form vivid, reallife memories (Conway, 2005; Roediger \& Marsh, 2003). Hence, a high sense of presence-including sensations of spatial presence, involvement and realness-means that
Fig. 12 Mean alpha amplitude $(8-13 \mathrm{~Hz})$ in $\mu \mathrm{V}$ in the latency range from 0 to $500 \mathrm{~ms}$ after stimulus onset. The error bars depict the standard error of the mean amplitude. Significant differences are marked $(* p<0.05 ; * * p<0.01)$ 
Fig. 13 Time-by-amplitude plot of the alpha-band response (8-13 Hz) from $200 \mathrm{~ms}$ before stimulus onset to $1200 \mathrm{~ms}$ after stimulus onset. Descriptively, a stronger reduction of the alpha amplitude was observed for both PC conditions compared to both VR conditions. The gray highlighted section marks the latency range of both significant main effects

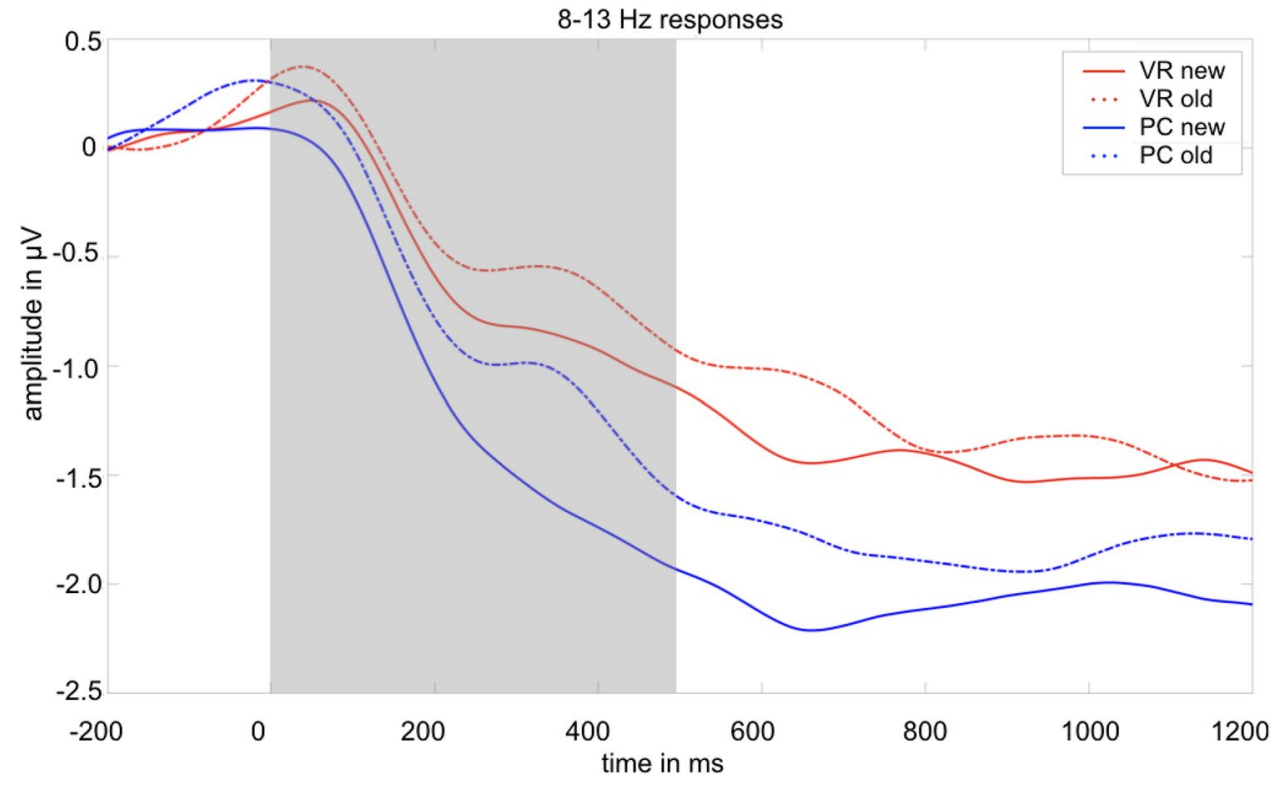

Fig. 14 Topography plot of alpha amplitude in $\mu \mathrm{V}$ (8-13 Hz) separately for factors group (VR vs. PC) and conditions (old vs. new) in the latency range from 0 to $500 \mathrm{~ms}$ after stimulus onset. Additionally, a difference plot of old minus new and PC minus VR is depicted. Black dots mark the electrodes which were included in the averaged amplitude
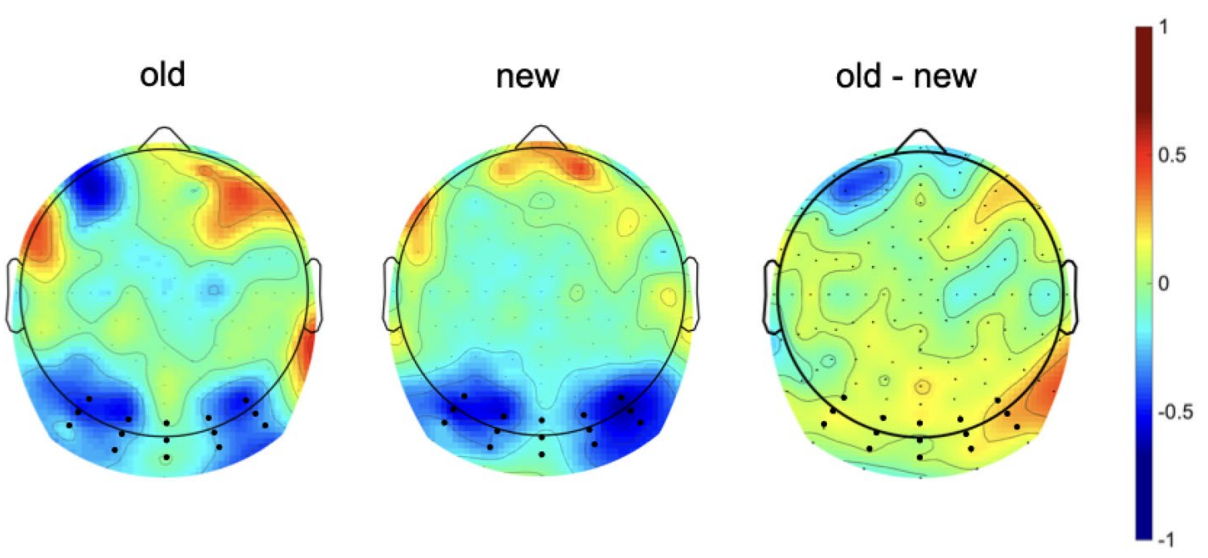

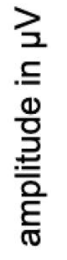
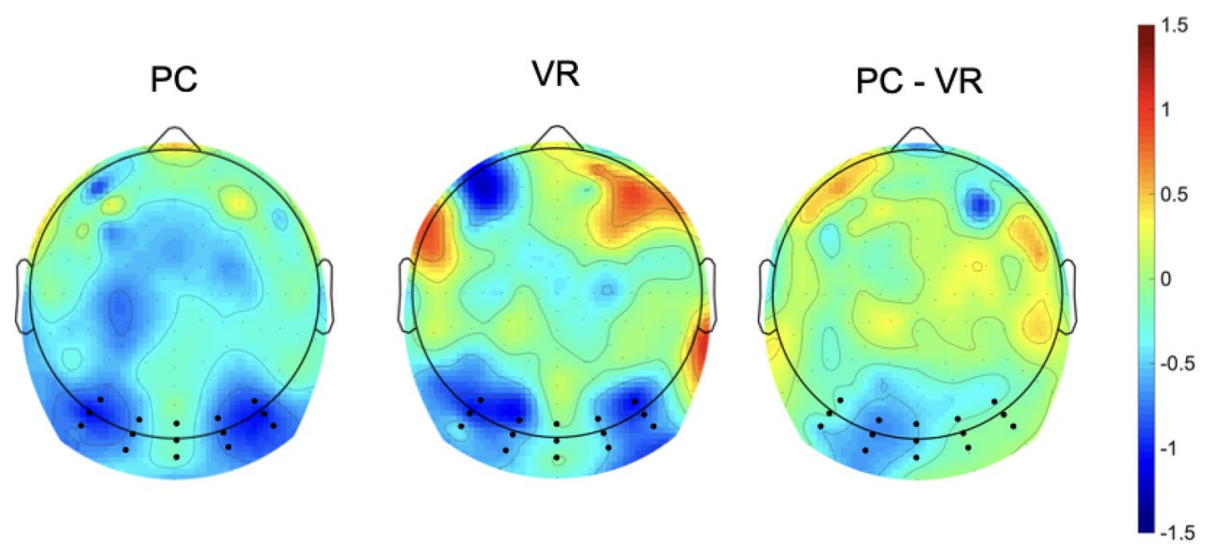

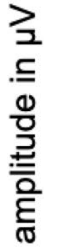

these events are potentially significant for the participant, consciously experienced and thus, might contribute to the formation of autobiographical memory.

However, at odds with previous research (Schöne et al., 2019; Smith, 2019; Kisker et al., 2019b), our study did not provide any behavioral evidence for this effect: Even though the VR group reported higher sensations of presence as compared to the PC group, we did not observe superior memory recall performance. Our results, with both groups having an accuracy of ca. $90 \%$, indicate a ceiling effect, limiting the detection of group differences (Bortz \& Döring, 2005). A possible cause of is effect might be the short retention 
interval between encoding and retrieval. Previous studies, which did not apply EEG measurements, chose longer retention intervals that included one or two sleeping periods (Schöne et al., 2019; Kisker et al., 2019b). It is possible that the process of forgetting irrelevant information had not yet started at the time of the EEG measurement or had at least not progressed very far (cf. Wang, Subagdja, Tan \& Starzyk, 2012). However, other studies have not been able to demonstrate this overall memory superiority of VR experiences either (LaFortune \& Macuga, 2018; Dehn et al., 2018; Kisker et al., 2019b). Differences regarding the findings of VR studies might be related to varying implementations of VR technology, ranging from highly immersive head-mounted displays and CAVE systems to less immersive desktop-VR implementations (Smith, 2019). Additionally, the level of multi-sensory sensations provided by the VR system might influence memory performance as well: For example, active navigation through a VR environment can have an additional positive effect on spatial memory, but not necessarily on factual memory (Plancher, Barra, Orriols \& Piolino, 2013). Moreover, some studies report a successful transfer of content learned in an immersive VR environment to real-life, and thus, to other than the encoding context (Ragan, Sowndararajan, Kopek \& Bowman, 2010; as cited in Smith, 2019), whereas other studies claim that knowledge transfer comes with a loss of performance (Lanen \& Lamers, 2018).

Even though VR experiences do not necessarily increase the retrieval success as measured by subjective reports, the immersive nature of VR yet might alter the mode of operation of the mnemonic mechanisms. Specifically, Kisker et al., (2019a) demonstrated by means of a remember/ know paradigm that participants who explored a virtual village in an immersive VR condition report predominantly recollection-based memory. Interestingly, recollection is hypothesized to be the associated retrieval mechanism of autobiographical memory (Roediger \& Marsh, 2003; Conway, 2005). Participants exploring the very same village in a PC condition reported predominantly familiarity-based memories (Kisker et al., 2019a). However, both groups in our experiment apparently employed the same retrieval strategies as the $d^{\prime}$-scores for recollection, familiarity and overall performance do not differ significantly.

Nevertheless, modulations of the frontal-midline theta effect might still indicate the involvement of different types of memory systems as well as associated encoding and retrieval strategies with respect to the encoding condition. As expected, we replicated the frontal-midline theta old/new effect in the PC condition: Old pictures evoked an early theta-band synchronization, whereas new pictures resulted in theta-band desynchronization. Hence, our findings replicate broad and stable evidence relating relatively higher theta-band amplitudes to the retrieval of old, and relatively lower amplitudes to the retrieval of new pictures in conventional laboratory settings (e.g. Gruber et al., 2008; Klimesch et al., 1997a, b, 2001a, b). The change of modality, i.e. encoding videos, but retrieval in response to picture presentation, did not markedly affect the theta old/new effect in the PC condition.

Remarkably, the theta old/new could not be observed in the VR condition. Specifically, new pictures led to the same theta-band response in both groups, indicating that the physical discrepancies between encoding in VR or under conventional conditions did not affect the paradigm per se or at least affected it to the same extent. Moreover, memory success did not account for the different electrophysiological responses as well, as both groups performed equally well in the recognition test. Accordingly, differences in the electrophysiological response must result from different underlying retrieval mechanisms and thus, differences in mnemonic processing of engrams encoded from either VR experiences or conventional laboratory events. Evidence that the absence of the theta old/new effect under VR conditions results from an altered mnemonic processing style as compared to the PC condition is obtained from the comparison of the response to old pictures between both groups. Regarding the $2-4 \mathrm{~Hz}$ frequency range, the presentation of old pictures led to a significant difference between relative synchronization in the PC group and in the VR group. Descriptively, the 4-7 Hz frequency range follows the same trend but did not reach significance. Hence, the theta old/new effect is modulated by the nature of the engram resulting from VR experiences and how these experiences are recalled.

As aforementioned, immersive VR experiences are considered to facilitate the formation of autobiographical memory. Associative autobiographical engrams are generated by highly self-relevant experiences (Roediger \& Marsh, 2003; Conway, 2005). They are characterized by richer content and are deeply interwoven into existing memory structures (McDermott et al., 2009; Roediger \& Marsh, 2003). Furthermore, they come with a broad set of functional properties, namely self-reflection, emotional evaluation and semantic processes (Svoboda et al. 2006). Frontal-midline theta has repeatedly been shown to reflect key-elements of autobiographical mnemonic processing. Specifically, it is associated with the recollection of personal events and contextual information (Guderian \& Düzel, 2005; Hsieh \& Ranganath, 2014; see also Roediger \& Marsh, 2003; Conway, 2005). In line with previous studies, our results indicate that the retrieval of immersive $3 \mathrm{D}-360^{\circ}$ experiences differs from the retrieval of conventional 2D laboratory events (Schöne et al. 2016; Schöne et al. 2019; Kisker et al., 2019b). Hence, the well-established theta old/new effect does not seem to be unrestrictedly applicable to VR experiences. It might rather 
serve as an index for cue-matching of previously exogenously processed pictorial stimuli: Experiences encoded in the laboratory are recalled and visually matched to the test stimuli, but are not inevitably associated with the vivid and multimodal character of autobiographical memories and thus, might not provide a holistic representation of real-life mnemonic processing.

The question remains, which processes change their mode of operation in response to the recall of VR experiences. The theta old/new effect is predominantly associated with retrieval success (e.g. Nyhus \& Curran, 2010). However, the VR and the PC group were likewise successful in the recognition task. As above mentioned, frontal-midline theta is associated with autobiographical mnemonic processing, but also regarded as an index for top-down control of memory retrieval (Klimesch et al., 1997b; Nyhus \& Curran, 2010). Specifically, early theta-band increases indicate an attempt or the effort demands to retrieve engrams rather than successful retrieval per se (Klimesch et al., 2001a; Nyhus \& Curran, 2010). Several studies investigating memory retrieval in general as well as the classical old/new effect in particular, explicitly differentiate retrieval effort and retrieval success (Klimesch et al., 2001a; Nyhus \& Curran, 2010; Rugg et al., 1998; Konishi, Wheeler, Donaldson \& Buckner, 2000). In particular, processes exclusively associated with retrieval success are engaged only if an attempted retrieval is successful. In contrast, retrieval effort refers to those processes engaged during a retrieval attempt per se, for example in recognition tasks, regardless of whether this attempt is successful or not (Rugg, Fletcher, Frith, Frackowiak \& Dolan, 1996). Accordingly, the absence of a difference in memory success does not rule out that the effort required to achieve the very same retrieval outcome may vary.

Hence, the difference in the theta-band response to old pictures between the VR condition and the PC condition could reflect the two types of retrieval differing with respect to their effort demands (Conway, 1996; Haque \& Conway, 2001; Conway \& Pleydell-Pearce, 2000). Immersive VR experiences as part of an extensive autobiographical associative network (PBM, Schöne et al., 2019) can be effortless and, most of all, directly retrieved. In contrast, the retrieval of conventional stimuli triggers the iterative verification process and the suppression of irrelevant information, thus coming in with higher effort to recall memories. Direct retrieval of autobiographical memory is based upon a pronounced and stable memory pattern (Conway \& Pleydell-Pearce, 2000) and enables spontaneous recall, which is rather automatic and effortless (Conway \& Pleydell-Pearce, 2000 as cited in Willander \& Larsson, 2007). It thus allows immediate recall of a cued memory. Generative or strategic retrieval of conventional stimuli, as observed in the PC condition, relies on central control of memory recall (Willander \& Larsson, 2007). To verify the cued memory, irrelevant information has to be suppressed, while mental representation and cue are matched (Norman \& Bobrow, 1979; Conway, 1996; Burgess \& Shallice, 1996).

This interpretation of a visually guided matching process gains further support from the difference in posterior alpha oscillations, associated with visual processing (e.g. Clayton et al., 2018). Matching mental representation and cue is reflected by a generally reduced posterior alpha amplitude in the PC condition compared to the VR condition. This reduced alpha amplitude, commonly regarded as cortical activity (e.g. Berger, 1929 as cited in Klimesch et al., 1997b), on the one hand reflects elevated attention (e.g. Klimesch, et al. 1997a; Fries, Womelsdorf, Oostenveld \& Desimone, 2008) and, on the other hand, successful suppression of irrelevant information (Sauseng et al., 2009; Jensen \& Mazaheri, 2010). Especially, the co-occurrence of higher frontal theta responses and posterior alpha activity has been interpreted as a response to higher cognitive load, with 2D environments exhibiting higher cognitive load as compared to 3D environments (Dan \& Reiner, 2017). Theta and alpha oscillations thus provide evidence for effortless and direct retrieval of immersive VR experience and a, in comparison, effortful and strategic retrieval of conventionally presented stimuli.

Nevertheless, the finding that the retrieval mechanisms underlying VR experiences and conventional laboratory experiences differ, does not invalidate previous well-established knowledge gained from conventional setups. Rather, it complements the immense insights from previous studies and demonstrates the delicate balance between high experimental control and ecological validity. Thus, controlled laboratory studies provide the foundations for understanding the complex mechanisms of human memory and are substantial for developing models. As a further refinement of these foundations, VR settings facilitate the transfer of experimental findings to everyday life and thus improve their generalizability and practicability.

\section{Conclusions}

As a conclusion, we replicated the well-established theta old/new effect in a conventional laboratory setting, manifested in relative theta-band synchronization for old, and relative desynchronization for new stimuli. However, this effect could not be replicated for the immersive VR condition: Theta-band responses were equal for old and new stimuli. Hence, the canonical theta old/new effect might not be unrestrictedly applicable to VR experiences and thus, might not provide a holistic representation of real-life processes. Accompanied by higher alpha activity as compared to the VR condition, the theta-band synchronization in the PC condition might rather reflect higher retrieval effort than 
retrieval success per se. In contrast to laboratory events, memories obtained from VR experiences are spontaneous and effortless retrieved. Additionally, participants of the VR condition reported a higher sense of presence, which might enhance the self-relevance of the VR experiences. Crucially, self-referential processing and a facile, effortless recall are characteristic of autobiographical memory. Therefore, the effortless recall of VR experiences might approximate real-life memory more closely as compared to memories obtained from the laboratory. However, the VR group did not perform better in the memory test, as former research suggested. Hence, our results suggest that the memory processes underlying VR experiences are qualitatively different from conventional laboratory experiences, but under which conditions VR leads not only to altered mechanisms but also to a better memory performance compared to conventional settings should be the subject of further research.

Author contributions All authors contributed to the study design. Testing and data collection were performed by JK. Data analyses were performed by JK under the supervision of BS and TG. JK and BS performed the data interpretation under the supervision of TG. JK drafted the manuscript, and BS and TG provided critical revisions. All authors approved the final version of the manuscript for submission.

Funding Open Access funding provided by Projekt DEAL. This research did not receive any specific grant from funding agencies in the public, commercial, or not-for-profit sectors.

Availability of data, material and code The datasets generated and analyzed during the current study are available in the Open Science Framework (OSF) repository, https://osf.io/q924w/?view_only=cc107 f7a927f472e8e68e85aaa059e97. Stimulus material was obtained from the Library for Universal Virtual Reality Experiments (luVRe, https ://www.psycho.uni-osnabrueck.de/fachgebiete/allgemeine_psychologi e_i/luvre.html) and can be accessed upon request.

\section{Compliance with ethical standards}

Conflict of interest All authors declare that they have no conflict of interest.

Statement of ethical approval All procedures performed in this study involving human participants were in accordance with the ethical standards of the local ethic committee of Osnabrueck University and with the 1964 Helsinki Declaration.

Consent to participate and to publish All individual participants gave informed written consent to participate in the study and to anonymized publication of the datasets.

Open Access This article is licensed under a Creative Commons Attribution 4.0 International License, which permits use, sharing, adaptation, distribution and reproduction in any medium or format, as long as you give appropriate credit to the original author(s) and the source, provide a link to the Creative Commons licence, and indicate if changes were made. The images or other third party material in this article are included in the article's Creative Commons licence, unless indicated otherwise in a credit line to the material. If material is not included in the article's Creative Commons licence and your intended use is not permitted by statutory regulation or exceeds the permitted use, you will need to obtain permission directly from the copyright holder. To view a copy of this licence, visit http://creativecommons.org/licenses/by/4.0/.

\section{References}

Alshaer, A., Regenbrecht, H., \& O'Hare, D. (2017). Immersion factors affecting perception and behaviour in a virtual reality power wheelchair simulator. Applied Ergonomics, 58, 1-12. https://doi. org/10.1016/j.apergo.2016.05.003.

Atkinson, R. C., \& Juola, J. F. (1973). Factors influencing speed and accuracy of word recognition. Attention and Performance, $I V$, 583-612.

Berger, H. (1929). Über das Elektroenkephalogramm des Menschen. Archiv für Psychiatrie und Nervenkrankheiten, 87(1), 527-570.

Bertrand, O., \& Pantev, C. (1994). Stimulus frequency dependence of the transient oscillatory auditory evoked responses $(40 \mathrm{~Hz})$ studied by electric and magnetic recordings in human. In: Oscillatory event-related brain dynamics (pp. 231-242). Boston: Springer.

Bohil, C. J., Alicea, B., \& Biocca, F. A. (2011). Virtual reality in neuroscience research and therapy. Nature reviews neuroscience, 12(12), 752-762.

Bortz \& Döring (2005). Forschungsmethoden und Evaluation (S. 182). Heidelberg: Springer-Verlag. ISBN 3-540-41940-3.

Bouchard, S., Talbot, J., Ledoux, A. A., Phillips, J., Cantamasse, M., \& Robillard, G. (2009). The meaning of being there is related to a specific activation in the brain located in the parahypocampus. In: Proceedings of Presence.

Burgess, A. P., \& Gruzelier, J. H. (1997). Short duration synchronization of human theta rhythm during recognition memory. NeuroReport, 8(4), 1039-1042.

Burgess, N., Maguire, E. A., Spiers, H. J., \& O’Keefe, J. (2001). A temporoparietal and prefrontal network for retrieving the spatial context of lifelike events. Neuroimage, 14(2), 439-453.

Burgess, P. W., \& Shallice, T. (1996). Response suppression, initiation and strategy use following frontal lobe lesions. Neuropsychologia, $34(4), 263-272$.

Busch, N. A., Herrmann, C. S., Müller, M. M., Lenz, D., \& Gruber, T. (2006). A cross-laboratory study of event-related gamma activity in a standard object recognition paradigm. Neuroimage, 33(4), 1169-1177.

Cabeza, R., Prince, S. E., Daselaar, S. M., Greenberg, D. L., Budde, M., Dolcos, F., \& Rubin, D. C. (2004). Brain activity during episodic retrieval of autobiographical and laboratory events: an fMRI study using a novel photo paradigm. Journal of Cognitive Neuroscience, 16(9), 1583-1594.

Cabeza, R., \& St Jacques, P. (2007). Functional neuroimaging of autobiographical memory. Trends in Cognitive Sciences, 11(5), 219-227.

Clayton, M. S., Yeung, N., \& Cohen Kadosh, R. (2018). The many characters of visual alpha oscillations. European Journal of Neuroscience, 48(7), 2498-2508.

Conway, M. A. (1996). Autobiographical knowledge and autobiographical memories. In D. C. Rubin (Ed.), Remembering our past: Studies in autobiographical memory (p. 67-93). Cambridge University Press. https://doi.org/10.1017/CBO9780511527913.003.

Conway, M. A. (2005). Memory and the self. Journal of Memory and Language, 53(4), 594-628.

Conway, M. A., \& Pleydell-Pearce, C. W. (2000). The construction of autobiographical memories in the self-memory system. Psychological Review, 107(2), 261. 
Curran, T., \& Hancock, J. (2007). The FN400 indexes familiarity-based recognition of faces. Neuroimage, 36(2), 464-471.

Dan, A., \& Reiner, M. (2017). EEG-based cognitive load of processing events in 3D virtual worlds is lower than processing events in 2D displays. International Journal of Psychophysiology, 122, 75-84.

Dehn, L. B., Kater, L., Piefke, M., Botsch, M., Driessen, M., \& Beblo, T. (2018). Training in a comprehensive everyday-like virtual reality environment compared to computerized cognitive training for patients with depression. Computers in Human Behavior, 79, 40-52.

Diemer, J., Alpers, G. W., Peperkorn, H. M., Shiban, Y., \& Mühlberger, A. (2015). The impact of perception and presence on emotional reactions: a review of research in virtual reality. Frontiers in Psychology, 6, 26.

Eckhorn, R., Reitboeck, H. J., Arndt, M. T., \& Dicke, P. (1990). Feature linking via synchronization among distributed assemblies: Simulations of results from cat visual cortex. Neural Computation, 2(3), 293-307.

Ernstsen, J., Mallam, S. C., \& Nazir, S. (2019). incidental memory recall in virtual reality: An empirical investigation. In: Proceedings of the Human Factors and Ergonomics Society Annual Meeting (Vol. 63, No. 1, pp. 2277-2281). Sage CA: SAGE Publications.

Felnhofer, A., Kothgassner, O. D., Schmidt, M., Heinzle, A. K., Beutl, L., Hlavacs, H., \& Kryspin-Exner, I. (2015). Is virtual reality emotionally arousing? Investigating five emotion inducing virtual park scenarios. International Journal of Human-Computer Studies, 82, 48-56.

Fries, P., Womelsdorf, T., Oostenveld, R., \& Desimone, R. (2008). The effects of visual stimulation and selective visual attention on rhythmic neuronal synchronization in macaque area V4. Journal of Neuroscience, 28, 4823-4835.

Gorini, A., Pallavicini, F., Algeri, D., Repetto, C., Gaggioli, A., \& Riva, G. (2010). Virtual reality in the treatment of generalized anxiety disorders. Studies in Health Technology and Informatics, 154, 39-43.

Greenberg, D. L., \& Rubin, D. C. (2003). The neuropsychology of autobiographical memory. Cortex, 39(4-5), 687-728.

Gromer, D., Reinke, M., Christner, I., \& Pauli, P. (2019). Causal interactive links between presence and fear in virtual reality height exposure. Frontiers in Psychology, 10, 141. https://doi. org/10.3389/fpsyg.2019.00141.

Gruber, T., Tsivilis, D., Giabbiconi, C. M., \& Müller, M. M. (2008). Induced electroencephalogram oscillations during source memory: familiarity is reflected in the gamma band, recollection in the theta band. Journal of cognitive neuroscience, 20(6), 1043-1053.

Guderian, S., \& Düzel, E. (2005). Induced theta oscillations mediate large-scale synchrony with mediotemporal areas during recollection in humans. Hippocampus, 15(7), 901-912. https://doi. org/10.1002/hipo.20125.

Haatveit, B. C., Sundet, K., Hugdahl, K., Ueland, T., Melle, I., \& Andreassen, O. A. (2010). The validity of $d$ prime as a working memory index: results from the "Bergen n-back task". Journal of Clinical and Experimental Neuropsychology, 32(8), 871-880.

Haque, S., \& Conway, M. A. (2001). Sampling the process of autobiographical memory construction. European Journal of Cognitive Psychology, 13(4), 529-547.

Harman, J., Brown, R., \& Johnson, D. (2017). Improved memory elicitation in virtual reality: new experimental results and insights. In: IFIP Conference on human-computer interaction (pp. 128-146). Springer, Cham.

Higuera-Trujillo, J. L., López-Tarruella Maldonado, J., \& Llinares Millán, C. (2017). Psychological and physiological human responses to simulated and real environments: A comparison between photographs, $360^{\circ}$ panoramas, and virtual reality. Applied Ergonomics, 65, 398-409. https://doi.org/10.1016/j.apergo.2017.05.006.
Hsieh, L.-T., \& Ranganath, C. (2014). Frontal midline theta oscillations during working memory maintenance and episodic encoding and retrieval. Neuroimage. https://doi.org/10.1016/j.neuroimage .2013.08.003.

Jacobs, J., Hwang, G., Curran, T., \& Kahana, M. J. (2006). EEG oscillations and recognition memory: Theta correlates of memory retrieval and decision making. Neuroimage, 32(2), 978-987.

Jacoby, L. L., \& Dallas, M. (1981). On the relationship between autobiographical memory and perceptual learning. Journal of Experimental Psychology: General, 110(3), 306.

Jensen, O., \& Mazaheri, A. (2010). Shaping functional architecture by oscillatory alpha activity: gating by inhibition. Frontiers in Human Neuroscience, 4, 186.

Jensen, O., \& Tesche, C. D. (2002). Frontal theta activity in humans increases with memory load in a working memory task. European Journal of Neuroscience, 15(8), 1395-1399.

Jones, T. C., \& Jacoby, L. L. (2001). Feature and conjunction errors in recognition memory: Evidence for dual-process theory. Journal of Memory and Language, 45(1), 82-102.

Junghöfer, M., Elbert, T., Tucker, D. M., \& Rockstroh, B. (2000). Statistical control of artifacts in dense array EEG/MEG studies. Psychophysiology, 37(4), 523-532.

Kisker, J., Gruber, T. \& Schöne, B. (2019a). Behavioral realism and lifelike psychophysiological responses in virtual reality by the example of a height exposure. Psychological Research. https:// doi.org/10.1007/s00426-019-01244-9.

Kisker, J., Gruber, T. \& Schöne, B. (2019b). Experiences in virtual reality entail different processes of retrieval as opposed to conventional laboratory settings: A study on human memory. Curr Psychol. https://doi.org/10.1007/s12144-019-00257-2

Klimesch, W., Doppelmayr, M., Pachinger, T., \& Ripper, B. (1997a). Brain oscillations and human memory: EEG correlates in the upper alpha and theta band. Neuroscience Letters, 238(1-2), 9-12.

Klimesch, W., Doppelmayr, M., Schimke, H., \& Ripper, B. (1997b). Theta synchronization and alpha desynchronization in a memory task. Psychophysiology, 34(2), 169-176.

Klimesch, W., Doppelmayr, M., Schwaiger, J., Winkler, T., \& Gruber, W. (2000). Theta oscillations and the ERP old/new effect: independent phenomena? Clinical Neurophysiology, 111(5), 781-793.

Klimesch, W., Doppelmayr, M., Stadler, W., Pöllhuber, D., Sauseng, P., \& Röhm, D. (2001a). Episodic retrieval is reflected by a process specific increase in human electroencephalographic theta activity. Neuroscience Letters, 302(1), 49-52.

Klimesch, W., Doppelmayr, M., Yonelinas, A., Kroll, N. E., Lazzara, M., Roehm, D., \& Gruber, W. (2001b). Theta synchronization during episodic retrieval: neural correlates of conscious awareness. Cognitive Brain Research, 12(1), 33-38.

Klimesch, W., Schimke, H., \& Schwaiger, J. (1994). Episodic and semantic memory: an analysis in the EEG theta and alpha band. Electroencephalography and Clinical Neurophysiology, 91(6), 428-441.

Konishi, S., Wheeler, M. E., Donaldson, D. I., \& Buckner, R. L. (2000). Neural correlates of episodic retrieval success. Neuroimage, 12(3), 276-286.

Krijn, M., Emmelkamp, P. M., Olafsson, R. P., \& Biemond, R. (2004). Virtual reality exposure therapy of anxiety disorders: A review. Clinical Psychology Review, 24(3), 259-281.

Krokos, E., Plaisant, C., \& Varshney, A. (2019). Virtual memory palaces: immersion aids recall. Virtual Reality, 23(1), 1-15.

Kvavilashvili, L., \& Ellis, J. (2004). Ecological validity and twenty years of real-life/laboratory controversy in memory research: A critical (and historical) review. History and Philosophy of Psychology, 9.

LaFortune, J., \& Macuga, K. L. (2018). Learning movements from a virtual instructor: Effects of spatial orientation, immersion, and 
expertise. Journal of Experimental Psychology: Applied, 24(4), 521.

Lanen, M., \& Lamers, M. H. (2018). Context-dependent memory in real and virtual reality. In: International Conference on virtual reality and augmented reality (pp. 177-189). Cham: Springer.

Lovett, A., Appleton, K., Warren-Kretzschmar, B., \& Von Haaren, C. (2015). Using 3D visualization methods in landscape planning: An evaluation of options and practical issues. Landscape and Urban Planning, 142, 85-94.

Makowski, D., Sperduti, M., Nicolas, S., \& Piolino, P. (2017). "Being there" and remembering it: Presence improves memory encoding. Consciousness and cognition, 53, 194-202.

McDermott, K. B., Szpunar, K. K., \& Christ, S. E. (2009). Laboratorybased and autobiographical retrieval tasks differ substantially in their neural substrates. Neuropsychologia, 47(11), 2290-2298.

Moscovitch, M., \& Winocur, G. (2002). The frontal cortex and working with memory. Principles of frontal lobe function, 188, 209.

Nilsson, N. C., Nordahl, R., \& Serafin, S. (2016). Immersion revisited: a review of existing definitions of immersion and their relation to different theories of presence. Human Technology, 12(2).

Norman, D. A., \& Bobrow, D. G. (1979). Descriptions: An intermediate stage in memory retrieval. Cognitive Psychology, 11(1), 107-123.

Nyhus, E., \& Curran, T. (2010). Functional role of gamma and theta oscillations in episodic memory. Neuroscience and Biobehavioral Reviews, 34(7), 1023-1035. https://doi.org/10.1016/j.neubi orev.2009.12.014.

Pan, X., \& Hamilton, A. F. D. C. (2018). Why and how to use virtual reality to study human social interaction: The challenges of exploring a new research landscape. British Journal of Psychology, 109(3), 395-417.

Parsons, T. D. (2015). Virtual reality for enhanced ecological validity and experimental control in the clinical, affective and social neurosciences. Frontiers in Human Neuroscience, 9, 660.

Plancher, G., Barra, J., Orriols, E., \& Piolino, P. (2013). The influence of action on episodic memory: a virtual reality study. Quarterly Journal of Experimental Psychology, 66(5), 895-909.

Plancher, G., \& Piolino, P. (2017). Virtual reality for assessment of episodic memory in normal and pathological aging. The role of technology in clinical neuropsychology, pp. 237-260.

Ragan, E. D., Sowndararajan, A., Kopper, R., \& Bowman, D. A. (2010). The effects of higher levels of immersion on procedure memorization performance and implications for educational virtual environments. Presence: Teleoperators and Virtual Environments, 19(6), 527-543.

Rauchs, G., Orban, P., Balteau, E., Schmidt, C., Degueldre, C., Luxen, A., \& Peigneux, P. (2008). Partially segregated neural networks for spatial and contextual memory in virtual navigation. Hippocampus, $18(5), 503-518$.

Riva, G., Mantovani, F., Capideville, C. S., Preziosa, A., Morganti, F., Villani, D., \& Alcañiz, M. (2007). Affective Interactions Using Virtual Reality: The Link between Presence and Emotions. CyberPsychology \& Behavior, 10(1), 45-56. https://doi. org/10.1089/cpb.2006.9993.

Roediger, H. L. III, \& Marsh, E. J. (2003). Episodic and autobiographical memory. In A. F. Healy \& R. W. Proctor (Eds.), Handbook of psychology: Experimental psychology, Vol. 4 (p. 475-497). John Wiley \& Sons Inc.

Rubin, D. C., Schrauf, R. W., \& Greenberg, D. L. (2003). Belief and recollection of autobiographical memories. Memory \& Cognition, 31(6), 887-901.

Rubin, D. C., \& Umanath, S. (2015). Event memory: A theory of memory for laboratory, autobiographical, and fictional events. Psychological Review, 122(1), 1.

Rugg, M. D., \& Curran, T. (2007). Event-related potentials and recognition memory. Trends in cognitive sciences, 11(6), 251-257.
Rugg, M. D., Fletcher, P. C., Allan, K., Frith, C. D., Frackowiak, R. S. J., \& Dolan, R. J. (1998). Neural correlates of memory retrieval during recognition memory and cued recall. Neuroimage, 8(3), 262-273.

Rugg, M. D., Fletcher, P. C., Frith, C. D., Frackowiak, R. S. J., \& Dolan, R. J. (1996). Differential activation of the prefrontal cortex in successful and unsuccessful memory retrieval. Brain, 119(6), 2073-2083.

Sauseng, P., Klimesch, W., Heise, K. F., Gruber, W. R., Holz, E., Karim, A. A., \& Hummel, F. C. (2009). Brain oscillatory substrates of visual short-term memory capacity. Current Biology, 19(21), 1846-1852.

Schöne, B., Schomberg, J., Gruber, T., \& Quirin, M. (2016). Eventrelated frontal alpha asymmetries: electrophysiological correlates of approach motivation. Experimental brain research, 234(2), 559-567.

Schöne, B., Wessels, M., \& Gruber, T. (2017). Differences between real-life and laboratory memory: Evidence from EEG and virtual reality. In Psychophysiology (Vol. 54, pp. S128-S128). 111 River ST, Hoboken 07030-5774, NJ USA: Wiley.

Schöne, B., Wessels, M., \& Gruber, T. (2019). Experiences in virtual reality: A window to autobiographical memory. Current Psychology, 38(3), 715-719.

Schöne, B., Kisker, J., Sylvester, R.S., Radtke, E.L., Gruber, T. (2020). Library for Universal Virtual Reality Experiments (luVRe): A standardized immersive $3 \mathrm{D} / 360^{\circ}$ picture and video database for VR based research. under review

Schubert, T., Friedmann, F., \& Regenbrecht, H. (2001). The experience of presence: Factor analytic insights. Presence: Teleoperators \& Virtual Environments, 10(3), 266-281.

Serino, S., \& Repetto, C. (2018). New trends in episodic memory assessment: immersive 360 ecological videos. Frontiers in Psychology, 9, 1878.

Slater, M., \& Wilbur, S. (1997). A framework for immersive virtual environments (FIVE): Speculations on the role of presence in virtual environments. Presence: Teleoperators \& Virtual Environments, 6(6), 603-616.

Slobounov, S. M., Ray, W., Johnson, B., Slobounov, E., \& Newell, K. M. (2015). Modulation of cortical activity in 2D versus 3D virtual reality environments: an EEG study. International Journal of Psychophysiology, 95(3), 254-260.

Smith, S. A. (2019). Virtual reality in episodic memory research: A review. Psychonomic Bulletin \& Review, 26(4), 1213-1237.

Svoboda, E., McKinnon, M. C., \& Levine, B. (2006). The functional neuroanatomy of autobiographical memory: A meta-analysis. Neuropsychologia, 44(12), 2189-2208.

Swets, J. A., Tanner, W. P., Jr., \& Birdsall, T. G. (1961). Decision processes in perception. Psychological Review, 68(5), 301.

Tallon-Baudry, C., \& Bertrand, O. (1999). Oscillatory gamma activity in humans and its role in object representation. Trends in Cognitive Sciences, 3(4), 151-162.

Tulving, E. (1983). Ecphoric processes in episodic memory. Philosophical Transactions of the Royal Society of London B Biological Sciences, 302(1110), 361-371.

Wang, W., Subagdja, B., Tan, A. H., \& Starzyk, J. A. (2012). Neural modeling of episodic memory: Encoding, retrieval, and forgetting. IEEE Transactions on Neural Networks and Learning Systems, 23(10), 1574-1586.

Willander, J., \& Larsson, M. (2007). Olfaction and emotion: The case of autobiographical memory. Memory \& Cognition, 35(7), 1659-1663.

Publisher's Note Springer Nature remains neutral with regard to jurisdictional claims in published maps and institutional affiliations. 